\title{
Toward a conceptual model relating chemical reaction fronts to water flow paths in hills
}

\author{
Susan L. Brantley ${ }^{1,2, *}$, Marina I. Lebedeva ${ }^{1}$, Victor N. Balashov ${ }^{1}$, Kamini Singha ${ }^{3}$, \\ Pamela L. Sullivan ${ }^{4}$, Gary Stinchcomb ${ }^{5}$
}


24 *Corresponding author. Tel.:+1 814865 1619; E-mail: brantley@ geosc.psu.edu.

\section{Abstract}

27 Both vertical and lateral flows of rock and water occur within eroding hills. Specifically,

28 when considered over geological timeframes, rock advects vertically upward under

29 hilltops in landscapes experiencing uplift and erosion. Once rock particles reach the land

30 surface, they move laterally and down the hillslope because of erosion. At much shorter

31 timescales, meteoric water moves vertically downward until it reaches the regional water

32 table and then moves laterally as groundwater flow. Water can also flow laterally in the

33 shallow subsurface as interflow in zones of permeability contrast. Interflow can be

34 perched or can occur during periods of a high regional water table. The depths of these

35 deep and shallow water tables in hills fluctuate over time. The fluctuations drive

36 biogeochemical reactions between water, $\mathrm{CO}_{2}, \mathrm{O}_{2}$, and minerals and these in turn drive

37 fracturing. The depth intervals of water table fluctuation for interflow and groundwater

38 flow are thus reaction fronts characterized by changes in composition, fracture density,

39 porosity, and permeability. The shallow and deep reaction zones can separate over

40 meters in felsic rocks. The zones act like valves that reorient downward unsaturated

41 water flow into lateral saturated flow. The valves also reorient the upward advection of

42 rock into lateral flow through solubilization. In particular, groundwater removes highly

43 soluble, and interflow removes moderately soluble minerals. As rock and water moves

44 through the system, hills may evolve toward a condition where the weathering advance

45 rate, $W$, approaches the erosion rate, $E$. If $W=E$, the slopes of the deep and shallow

46 reaction zones and the hillsides must allow removal of the most soluble, moderately 
47 soluble, and least soluble minerals respectively. A permeability architecture thus emerges

48 to partition each evolving hill into dissolved and particulate material fluxes as it

49 approaches steady state.

50 


\section{Introduction}

53 The largest supply of accessible, potable water is contained in rocks beneath our feet

54 (Fetter, 2001). To learn to sustain our water supply, we need conceptual and numerical

55 models that describe how water is stored and how it moves through rock and regolith. At

56 present, we cannot predict such hydrologic partitioning because of the extremely

57 heterogeneous distribution of subsurface rock material (Gleeson et al., 2015).

59 A major thrust of critical zone science is to develop models of weathering and landscape

60 evolution to allow a priori predictions of the architecture of mineralogy, porosity, and

61 permeability in regolith (e.g., Carson and Kirkby, 1972; Anderson et al., 2002;

62 Amundson, 2004; Mudd and Furbish, 2004; Godderis et al., 2006; Lebedeva et al., 2007;

63 Minasny et al., 2008; Pelletier, 2008; Yoo and Mudd, 2008; Burke et al., 2009; Lebedeva

64 et al., 2010; Brantley and Lebedeva, 2011; Rasmussen et al., 2011; Lebedeva and

65 Brantley, 2013; Duffy et al., 2014; Rempe and Dietrich, 2014). Here, we use the term

66 regolith to mean all the fragmented and altered material that overlies pristine bedrock

67 (protolith). Major advances have also been made in the last two decades in relating

68 hillslope hydrology to the compartmentalization of water chemistry inside hills (e.g.,

69 Hooper et al., 1990; McDonnell, 1990; Tromp-van Meerveld and McDonnell, 2006;

70 Legout et al., 2007; Ayraud et al., 2008; Katsura et al., 2008; Salve et al., 2012; van

71 Meerveld et al., 2015). However, these two sets of approaches have largely been

72 separate, and we generally cannot relate the flux of solutes out of a catchment to where

73 weathering is occurring at depth (e.g., Calmels et al., 2007; Legout et al., 2007). This 
74 lack of detailed understanding of weathering inside individual hills may have

75 implications at global scales (Torres et al., 2014).

77 Given this state of the science, when catchments are studied, the hydrologist does not

78 know which of several conceptual models to apply (Welch and Allen, 2014). For upland

79 systems, for example, researchers have used (i) a bucket-type model where the subsurface

80 is not layered, (ii) a one-layer approach where subsurface flow is restricted to an upper

81 layer and bedrock is considered impermeable, or (iii) a two-flow approach where lateral

82 flow occurs in an upper layer and in a lower layer (Banks et al., 2009).

84 Here, we explore the idea that the compartments and layers described by hydrologists

85 (Dewandel et al., 2006; Ayraud et al., 2008) and water masses described by river

86 investigators (Calmels et al., 2007) may be related to reaction fronts mapped at depth by

87 geochemists (Brantley et al., 2013a). These reaction fronts are depth intervals in the

88 subsurface where reactions are occurring. Beneath hills in humid systems where net

89 unsaturated water flow is vertical, for example, minerals can dissolve or precipitate to

90 form reaction fronts that roughly mimic the land surface (Figs. 1, 2). In the presence of

91 very impermeable rock, solutes are transported across reaction fronts by diffusion; in

92 contrast, in high-flow, permeable rock, solute transport is dominated by advection. In this

93 paper we explore the idea that reaction fronts for different minerals separate over space

94 (Figs. 2B,C) when solutes move through the fronts largely by advection. In contrast, the

95 fronts remain co-located within tens of centimeters (Fig. 2A) when solute transport is 
96 largely by diffusion. We try to relate these fronts to hillslope hydrology by developing a

97 conceptual model.

99 Specifically, the mineral assemblages observed across reaction fronts can reveal

100 information about the cumulative water flows. These mineral assemblages can magnify

101 relative differences in fluid flow in different layers because the solubility of minerals is

102 small when considered on a volume/volume basis (volume of dissolved mineral / volume

103 of water). Such dimensionless solubilities generally are $\sim 10^{-3}$ or smaller (Berner, 1981).

104 This means that the volume of water that must flow through a given rock matrix to

105 dissolve and remove a mineral is $>10^{3}$ times the volume of mineral that is dissolving.

106 Small differences in reacted mineral volumes across depth intervals thus can record and

107 magnify differences in cumulative water flow.

108

109 We exemplify these ideas with field data for shale, granite, and diabase (Fig. 2). We

110 emphasize one physiographic province, the Piedmont of the eastern U.S.A., where long

111 exposure times and low erosion rates are likely to have resulted in geomorphological

112 steady state (Pavich, 1986; Pavich et al., 1989). We also discuss an example from the

113 Susquehanna Shale Hills Critical Zone Observatory situated just to the north of Virginia

114 where isotope-based estimates of the erosion rate and the soil production rate at ridgetops

115 are equal within error (West et al., 2013).

116

117 The point of the paper is to use a critical zone science approach, i.e., an approach that

118 explores how geochemical, hydrological, and geomorphological observations can 
119 illuminate the question of water flow inside hills. Although the treatment is qualitative in

120 comparison to state-of-the-art geochemical, hydrological, or geomorphological studies,

121 the concepts are explored to stimulate the development of better conceptual models for

122 hills.

123

124 In the models presented here, we first consider hills where mean annual precipitation

125 (MAP) exceeds potential evapotranspiration (ET), and where regolith formation

126 conceptualized in one or two dimensions (1D or 2D) consists of net water flow

127 downward occurring at relatively fast timescales and net rock material flow upward at

128 geologic timescales. Vegetation also takes up material but this represents a short-term

129 cycle ( $<100$ years) in which material is stored and returned to the system; this biotic cycle

130 is thus largely ignored. Throughout the paper we emphasize models where rates of uplift

$131(U)$, weathering $(W)$, erosion $(E)$, and channel incision $(I)$ are all equal. We call these

132 steady state models because aspects of the regolith and its distribution do not vary with

133 time; others refer to models where $E=U$ as dynamic equilibrium (Hack, 1960; Pain and

134 Ollier, 1996). We extend such ideas by including implications of weathering advance

135 rates in this steady state model.

136

137 2. A geochemical model of hillslope evolution

138 Since the 1980s, 1D numerical reactive transport models have described weathering

139 caused by interaction of meteoric water with minerals (e.g., Lichtner, 1988; Lichtner and

140 Waber, 1992; Steefel, 1993). More recently, reactive transport models have been used to

141 describe regional-scale weathering under landscapes (e.g., Maher, 2011). Reactive- 
142 transport models have also been extended to include physical erosion (Waldbauer and

143 Chamberlain, 2005; Lebedeva et al., 2007; Hilley et al., 2010; Lebedeva et al., 2010;

144 Brantley and Lebedeva, 2011; Brantley et al., 2013b). Here we emphasize published

145 models from Lebedeva and Brantley and coworkers (Lebedeva et al., 2007; Lebedeva et

146 al., 2010; Lebedeva and Brantley, 2013) and we refer to those models throughout as

147 L\&B. In these weathering + erosion models, the rate of change of regolith thickness is

148 simulated as the balance between the rate that weathering advances into the rock ( $W$, in

149 units of $\left.\mathrm{L} \mathrm{T}^{-1}\right)$ and the rate of erosion, $E\left(\mathrm{~L} \mathrm{~T}^{-1}\right)$. When $W=E$, the regolith thickness $H$ is

150 constant in time (i.e., steady state). Although such a steady state has generally not been

151 proven for individual sites, the presence of moderately thick regolith in many locations

152 documents that neither $W>>E$ nor that $E>>W$ for geologically long periods of time.

153 This in turn suggests that feedback mechanisms may couple erosion at the land surface to

154 weathering and vice versa in some locations (e.g., Carson and Kirkby, 1972; Stallard,

155 1995; Fletcher et al., 2006; Lebedeva et al., 2007; Fletcher and Brantley, 2010; Behrens

156 et al., 2015). Thus, regolith-mantled systems may not constantly maintain $W=E$, but

157 they may commonly be moving toward such a steady state, driven by feedbacks.

158 Feedbacks could include the effects of porewater chemistry, soil gas chemistry, particle

159 size or fracture spacing (Fletcher et al., 2006; Fletcher and Brantley, 2010; Behrens et al., 160 2015).

162 To explore controls on weathering and eroding systems, L\&B formulated models that

163 contain only a few minerals. In several models, they considered rock composed of one

164 inert (quartz) and one reactive mineral (albite feldspar). Albite reacts to form a soil 
165 mineral (kaolinite) plus an aqueous solute component $\left(\mathrm{NaSi}_{2}\right)$. Some $\mathrm{L} \& \mathrm{~B}$ models also

166 include a redox-active mineral component $(\mathrm{FeO})$. These four-mineral models focus on the

167 two most essential chemical weathering reactions: acid consumption (albite to kaolinite)

168 and oxidation (ferrous iron to ferric iron minerals). Quartz is included to maintain

169 isovolumetric weathering.

170

171 Weathering reactions occur in the model as soluble reactants are transported to mineral

172 surfaces, and products are transported away from the surfaces by advection or diffusion

173 or both. In L\&B models with advection, the advective velocity is held constant even

174 though porosity and mineral surface area change during reaction (Lebedeva et al., 2007).

175

176 For example, L\&B explored the distribution of regolith on a convex-upward hillslope

177 (Lebedeva and Brantley, 2013). Water flows downward at a constant velocity. Solute is

178 transported by this vertical advection as well as by vertical and horizontal diffusion. Fig.

1793 shows numerical simulations from such a reactive-transport problem formulated for a

180 quartz+albite protolith bounded by a hillslope surface that can vary over space and time.

181 Here $y$ and $x$ are measured in the vertical and horizontal directions respectively, and $t$ is

182 time. The hillslope evolves based on the following 2D equation:

183

184

$$
\frac{\partial(\phi C)}{\partial t}=\frac{\partial}{\partial x}\left(D \phi \frac{\partial C}{\partial x}\right)+\frac{\partial}{\partial y}\left(D \phi \frac{\partial C}{\partial y}\right)-\frac{\partial\left(C q_{x}\right)}{\partial x}-\frac{\partial\left(C q_{y}\right)}{\partial y}+j(C, \eta)
$$


186 where $D\left(\mathrm{~m}^{2} / \mathrm{s}\right)$ is the diffusion coefficient in the aqueous pore solution reduced by

187 tortuosity, and $q_{x}$ and $q_{y}(\mathrm{~m} / \mathrm{s})$ are the horizontal and vertical (directed downward)

188 components of the Darcy velocity of the pore fluid, respectively. Both components are

189 included in the equation for completeness, although $q_{x}$ is set to zero in the model. The

190 concentration of the solute released to the pore fluid is $C$ and the albite reaction rate is $j$

191 (mol $\left./ \mathrm{m}^{3} \mathrm{~s}\right)$. The extent of reaction, $\eta$ (unitless), is defined as $\eta=\left(\rho^{0}-\rho\right) / \rho^{0}$. It

192 changes with time as follows:

193

$$
\frac{\partial \eta}{\partial t}=\frac{j(C, \eta)}{\rho^{0}}
$$

194 Here, $\rho=\phi_{a b} / V_{a b}^{0}$ is the concentration of reacting mineral (albite) in the rock

195 (superscript 0 refers to protolith composition), $\phi_{a b}$ is the volume fraction of albite in a

196 rock, and $V_{a b}^{0}$ is its specific volume. The concentration of the solute in pore fluid at the

197 land-atmosphere surface is maintained constant and equal to $C^{R}$.

199 Mass balance on the hillslope is written in terms of hillslope elevation $Y$ as:

$$
\rho_{s} \frac{\partial Y}{\partial t}=\kappa \rho_{s} \frac{\partial^{2} Y}{\partial x^{2}}+\left(\rho_{s}-\rho_{r}\right) \frac{\partial \Delta B_{2}}{\partial t}-F(C, \eta)
$$

203 Here, $\rho_{r}$ and $\rho_{s}$ are the bulk density of the rock and the kaolinite-containing soil,

204 respectively; $\kappa\left(\mathrm{m}^{2} \mathrm{y}^{-1}\right)$ is the soil diffusivity (i.e., Gilbert's constant) that is used in the 205 diffusion-like transport law describing soil flux along a hillslope (Carson and Kirkby, 206 1972). The position of the bedrock surface, $\Delta B_{2}(x, t)$ is defined as the point where 
207 protolith has experienced $0 \%$ alteration (Fig. 1). The function $F$ describes the rate of

208 change in material mass because of chemical processes. Assuming (i) that the solute flux

209 is a small contributor to elevation change compared to the physical erosion flux or (ii)

210 that weathering is isovolumetric, $F$ can be neglected in this equation. The weathering

211 advance rate, $W$, defines the elevation of unweathered material $\Delta B_{2}$ :

212

$$
\frac{\partial \Delta B_{2}}{\partial t}=-W
$$

215 At steady state, the regolith thickness, $H=r-\Delta B_{2}$, is constant. Under this condition and

216 neglecting the term $F$ (Carson and Kirkby, 1972; Follain et al., 2006), Lebedeva and

217 Brantley (2013) separated the systems of Eqs. (1)-(2) and (3)-(4) and derived the equation

218 for the steady state (parabolic) hillslope:

$$
\mathrm{Y}_{s}(x)=-\frac{\rho_{r} E}{2 \rho_{s} \kappa} x^{2}+Y_{L}+\frac{\rho_{r} E L^{2}}{2 \rho_{s} \kappa}
$$

222 Here, $Y_{L}$ is the elevation at the channel bottom at $x=L$. As defined above, $E\left(\mathrm{LT}^{-2}\right)$ is the

223 velocity of lowering of the hill because of physical erosion. The boundary condition at

224 the channel $(x=L)$ is defined so that $E=$ the incision rate $I$ (i.e., $\left.Y=H_{L}-I t\right)$. Lebedeva

225 and Brantley (2013) explore the idea that weathering advance is controlled by solubility

226 and geochemical kinetics coupled with transport in a pore fluid. Note that in contrast to

227 the multiple reaction fronts shown in Fig. 2 and discussed later in this paper, the L\&B 
228 model was formulated for the simplified rock, quartz + albite transforming to quartz +

229 kaolinite, so only one reaction front occurs in the system. The elevation of this single

230 front is referred to here as $\Delta B_{2}$.

231

\section{3. Simulated hillslopes from the $L \& B$ model}

233 Simulated steady state hillslopes calculated using Eq. (5) and Eqs. (1) - (2) at the

234 lowering hillslope surface are shown for various values of erosion $E$ and vertical Darcy

235 velocity $q_{y}$ in Fig. 3 . All other parameters $\left(\kappa, \rho_{r}, \rho_{s}, Y_{L}, L, D\right)$ were held constant, and

236 water was only allowed to flow vertically. The hillform varies only with $E$ because the

237 topography is affected by erosion but not by chemical weathering as described for Eq.

238 (5). In contrast, the extent of alteration of the hill varies not only with $E$ but also with $q_{y}$.

239 This is because $E$ sets the residence time in the weathering zone and $q_{y}$ sets the volume of

240 water that interacts with the mineral while it is in that zone.

242 All model predictions were calculated with reasonable kinetic constants for a rock with

$24340 \%$ albite, 50\% quartz, and 10\% porosity (Lebedeva et al., 2007). Fig. 3 leads to two

244 important observations. First, the hillslope becomes steeper as $E$ increases (Figs. 3A-3E).

245 In fact, at steady state, the ratio of relief, $r$, divided by length, $L$, of the hill derived from

246 mass balance on the hill (Eq. 5) yields:

247

$$
\frac{r}{L}=\frac{E L}{\kappa} \frac{\rho_{r}}{2 \rho_{s}} \approx \frac{E L}{\kappa}
$$


250 The ratio $r / L$ is roughly the slope of the convex-upward hill surface. The value of the

251 slope of the hill can be considered an emergent property of the eroding system.

253 The second observation is that a thicker regolith develops at valley and at ridgetop when

254 infiltration, $q_{y}$, increases but $E$ is maintained constant (Figs. 3E,F vs. 3G,H). Above a

255 critical value of $q_{y}$, however, the rate of erosion is slower than weathering advance

256 (Lebedeva et al., 2010), and regolith thickens with time without reaching steady state (not

257 shown). At the other extreme where $I(=E)$ increases to high values, advection velocity

258 becomes less significant in affecting regolith thickness. Eventually, for a given lithology

259 exposed to a given climate, a critical erosion rate is reached above which the weathering

260 rate can no longer keep up with the erosion rate. At this point, bedrock emerges at the

261 land surface (not shown). Like the slope of the hill, the regolith thickness is an emergent

262 property of the system.

263

264 Another emergent property that characterizes a system and is easily observed is the extent

265 of weathering of material emerging at the land surface, $\eta_{\max }$. For an easily erodible rock

266 that contains only moderately soluble minerals (Figs. 3B,D,F-H), mineral grains pass

267 through the weathering zone without dissolving away entirely by the time they reach the

268 land surface: this results in 'incompletely developed profiles' because depletion of the

269 mineral does not equal $100 \%$ at the land surface (Brantley and White, 2009). For this

270 case, $\eta_{\max }<1$ and such a regime has been termed 'weathering-limited' (Lebedeva and

271 Brantley, 2013) or 'reaction-limited' (Hilley et al., 2010). An example where the

272 dominant reactive mineral in protolith (illite) comprises an incompletely developed 
273 profile at both the ridge and valley is observed in the Susquehanna Shale Hills Critical

274 Zone Observatory in Pennsylvania in the USA (Jin et al., 2010a). At that site the

275 dominant lithology is shale - a rock that is easily eroded but which contains relatively

276 insoluble minerals. This site is discussed further in section 5.

277

278 The opposite case of a lithology with a high capacity to be weathered but a lower

279 capacity to be eroded will evolve to a 'completely developed profile'. In this type profile,

280 the reactive mineral approaches $100 \%$ depletion at the land surface at ridge and at valley

281 (Figs. 3A,C,E): in other words, the time needed for the mineral grains to move from the

282 underlying protolith interface upward to the land surface is long enough that the mineral

283 dissolves away completely and concentration drops to $0 \%$ at the land surface. This

284 regime has been termed 'erosive transport-limited' by L\&B because neither the extent of

285 reaction at the regolith-air surface $\left(\eta_{\max }\right)$ nor the hill-integrated alteration rate is a

286 function of the dissolution rate constant. The idea of a regime that is limited by the rate of

287 physical removal of material from the weathering zone was introduced long ago (e.g.,

288 Stallard and Edmond, 1983) and has been labeled with several names. In this regime,

$289 \eta_{\max }=1$ and can only be lowered from 1 by increasing $E$.

291 An intermediate mixed-control regime can occur such that the profile for the reacting

292 mineral is completely developed at the ridgetop $\left(\eta_{\max }=1\right)$ but is incompletely developed

293 at the valley $\left(\eta_{\max }<1\right)$. In this case the overall hill-integrated alteration rate is affected by

294 changes in weathering rate constants and in erosional efficiency, i.e., the mixed-control or

295 transition regime of L\&B. Fig. 3H approaches this case. Examples of this are observed 
296 on metapelites, granites, and diabase in the Piedmont of Maryland and Virginia in the

297 USA. (Cleaves et al., 1970; Pavich et al., 1989) where bedrock is exposed in the channel

$298\left(\eta_{\max }=0\right)$ but reactions go to completion under the ridgetop $\left(\eta_{\max }=1\right)$. Such cases are

299 discussed in section 5.

300

301 The fraction of mass solubilized from these hills varies under these different regimes. In

302 the literature, this fraction has been referred to as the chemical depletion fraction or CDF

303 (Riebe et al., 2001). The CDF has been calculated to describe samples, pedons, hillslopes,

304 and watersheds. For any given sample, CDF is identical to the weathering intensity $\eta$

305 (Brantley and Lebedeva, 2011), and can thus vary from 0 to 1. For our model hills, the

306 CDF is the mass fraction of the hill lost as solute (see supplemental information). Our

307 steady state models show that if $E$ is increased but $q_{y}$ is maintained constant, CDF

308 decreases because the residence time of rock material in the weathering zone decreases.

309 For a 1D model with constant $q_{y}$, for example, CDF varies approximately as $1 / E$ in the

310 weathering-limited regime (CDF $<1$ in Fig. 4A).

311

312 If $q_{y}$ increases while $E$ is held constant in our steady state hills, the value of $W\left(\mathrm{~L} \mathrm{~T}^{-1}\right)$ still

313 remains constant. This is because at steady state, $E=W\left(\mathrm{~L} \mathrm{~T}^{-1}\right)=$ a constant. Thus, as $q_{y}$

314 increases at constant $E$, the value of CDF integrated over the entire hill must increase to

315 increase the weathering solute flux out of the hill while maintaining the same $W$ (Fig.

316 4A). For example, Fig. 4B shows that CDF increases almost linearly with $q_{y}$ at constant

$317 E$ in the weathering limited or mixed-control regimes until the regime of erosive transport

318 limitation where $\mathrm{CDF}=1$. It may seem confusing that the weathering advance rate $W$ can 
319 remain constant at the same time that the fraction of hill volume that leaves the hill as

320 solute (CDF) increases. In effect, in these steady state hills, $W$ is constrained to always

321 equal $E$, and $E$ determines the residence time that particles remain in the weathering zone.

322 The extent of reaction is dictated by the volume of water that interacts with the mineral in

323 the zone, i.e., it depends on $q_{y}$. For higher $q_{y}$, more weathering occurs during the transit of

324 particles through the zone and results in a higher extent of reaction at the regolith-air

325 surface $\left(\eta_{\max }\right)$, even though $W$ remains constant.

326

327 In effect, the CDF is another emergent property of the steady state system. For this

328 model, the CDF is determined by (i) $q_{y}$, (ii) lithology, and (iii) imposed uplift or erosion

329 rate (where $U=E=W$ ). For the model hill, advection, lithology, and uplift rate set three

330 important conditions with respect to the reactive mineral: respectively, (i) the volume of

331 water interacting with the mineral, (ii) the initial volumes of minerals, and (iii) the

332 duration of interaction with weathering fluids. Thus, the hill is determined by (i) climate,

333 (ii) reactive mineral content, and (iii) tectonics. Although we emphasize the climate

334 variable $q_{y}$ rather than temperature, temperature is implicitly important because

335 temperature affects the reaction kinetics and solubilities.

336

337 In addition to CDF, the porosity is also an emergent property that develops in the steady

338 state hill as it isovolumetrically weathers. In these steady state models, porosity develops

339 as a function of $q_{y}$, reactive mineral content $\left(\phi_{a b}^{0}\right)$, and protolith porosity ( $\left.\phi_{\text {initial }}\right)$ to allow

340 the weathering advance rate $W$ to equal the erosion rate $E$. Because we are assuming

341 isovolumetric weathering, as $q_{y}$ and $\eta_{\max }$ increase, the porosity, $\phi$, of material remaining 
342 behind that is eroding also increases: $\phi=\phi_{\text {initial }}+\phi_{a b}^{0}\left(1-\frac{V_{k a o}^{0}}{2 V_{a b}^{0}}\right) \eta \approx \phi_{\text {initial }}+0.5 \phi_{a b}^{0} \eta$. Here,

$343 V_{k a o}^{0}$ and $V_{a b}^{0}$ are the specific volumes of the minerals.

345 Just as $E$ controls the slope of the hill surface, $q_{y}$ controls the slope of another emergent

346 property, the surface of the (unweathered) protolith. At high $q_{y}$, the slope of the protolith

347 surface becomes shallower (Fig. 3). This trait is exemplified in the weathering of

348 schistose rocks in the Piedmont of the eastern USA. (Pavich et al., 1989). These rocks

349 show evidence of deep infiltration (high $q_{y}$ ), including deep alteration along foliations,

350 schistosity, and cleavage (Nutter, 1969). Consistent with the prediction of a shallow

351 protolith slope, Pavich et al. showed a schematic of a hill on metapelite that appears

$352100 \%$ weathered (Pavich et al., 1989). An example of weathering schist from the

353 Piedmont is discussed in section 8.

355 At high $q_{y}$, L\&B models also show that the depth interval over which chemical reaction

356 occurs (the reaction front where $0<\eta<1$ ) becomes thicker. This reaction front

357 thickness along the hillslope is thus another emergent property of the steady state system.

358 Once $q_{y}$ increases to the point that $\eta_{\max }=1$ (Fig. 3E), increasing $q_{y}$ no longer can result in

359 an increase in porosity as discussed in the last paragraph. Instead, for the hill to achieve

360 steady state, an increase in $q_{y}$ only results in thicker regolith at ridge and at valley.

362 So far, we held the composition constant at 50\% quartz in the model used to generate Fig.

363 3. We therefore next explore the effect of $\%$ quartz in the L\&B model under conditions 
364 of constant $E$ and $q_{y}$ (Figs. 4C, 5). As \% quartz increases, the ridgetop regolith and the

365 reaction front thicken. These simulations are consistent with observations within the

366 Virginia Piedmont (Pavich et al., 1989). In that setting, regolith depth under interfluves

367 increases with the quartz content on rocks of different lithology as shown in Fig. 6. In

368 another example, the regolith and the reaction fronts on granitic rock in Panola Mountain,

369 Georgia (28\% quartz) are thinner than observed at Davis Run, Virginia (41\% quartz),

370 USA (White et al., 2001; Bazilevskaya et al., 2013). Both of these systems are

371 weathering in the Piedmont with roughly similar erosion and precipitation rates, i.e.,

372 similar $E$ and $q_{y}$ (Bacon et al., 2012). The GA and VA field settings demonstrate that

373 reaction front and regolith thicknesses are emergent properties of hills.

375 As discussed above, the $\mathrm{L} \& \mathrm{~B}$ model is based on the assumption that rates of advection

376 are everywhere the same and everywhere vertical. This latter assumption is only roughly

377 true because permeability changes significantly within rock material inside hills and

378 zones of lateral flow are common (Pain and Ollier, 1996). In fact, White et al. (2001)

379 argued that much of the permeability contrast inside hills developed on granitic bedrock

380 arises because of mineral reaction. Specifically, changes in porosity and permeability

381 may be especially important at reaction fronts where mineral abundances vary. Such

382 fronts can be stacked or nested when considered in 1D or 2D respectively (Brantley et al.,

383 2011; Brantley et al., 2013a). We explore reaction fronts in hills (Figs. 1, 2) in the next

384 section, and then we explore how they may be related to water flow and water tables in

385 the following sections. 


\section{Reaction fronts}

388 4.1.The geometry of reaction fronts

389 Here we consider weathering profiles and reaction fronts under ridges (Fig. 2). The

390 nature of the bottom of the front where the reaction initiates is dictated by the upward

391 flow of solid earth materials and downward flow of meteoric waters. In particular, as

392 rock moves upward as a result of exhumation, it fractures. For example, at $\sim 2 \mathrm{~km}$ depth

393 in granites in the northeastern USA, the average microcrack orientation transforms from

394 vertical to horizontal as the stress state changes during exhumation (Nadan and Engelder,

395 2009). At shallower depths, larger sheet fractures oriented parallel to the land surface

396 begin to open in the rock (Molnar et al., 2007; Nadan and Engelder, 2009; Lachassagne et

397 al., 2011). As meteoric water flows through such thermoelastic and topographic cracks

398 as well as matrix pores and tectonic microcracks, the rock material weathers and forms

399 reaction fronts (Ollier, 1967; Fletcher et al., 2006; Ayraud et al., 2008; Navarre-Sitchler

400 et al., 2015). Such reaction fronts can roughly mimic the land surface but they are also

401 affected by physical heterogeneities such as veins, fractures, and faults, so that the

402 reaction fronts are rough at all scales (Navarre-Sitchler and Brantley, 2007; Navarre-

403 Sitchler et al., 2013). For example, where fracture zones allow deeper infiltration (Welch

404 and Allen, 2014), reaction fronts are deeper compared to the surrounding unfractured

405 zones (Dewandel et al., 2006; Drake et al., 2009).

407 For an upland system developed on one rock type, several reaction fronts can nest one

408 within the other. Each front is a curved surface that somewhat parallels the landscape;

409 however, the relief of deeper reaction fronts is generally lower than that of shallower 
410 fronts (Chigira, 1990; Chigira and Sone, 1991; Chigira and Oyama, 1999; Taylor and

411 Eggleton, 2001; Ayraud et al., 2008; Drake et al., 2009; Brantley et al., 2013a). While

412 reaction fronts tend to be nested under convex-up hilltops, the fronts may cross under

413 valleys where water flow paths merge (Chigira and Oyama, 1999; Brantley et al., 2013a).

414

415 The exact geometry of such reaction fronts is unknown. However, geophysical tools can

416 be used to assess the depths of weathering and fracturing because rock properties change

417 due to these processes. For example, weathering and fracturing can cause the seismic

418 velocities of rock material to decrease (Holbrook et al., 2014) and mapping of such low-

419 velocity zones can therefore sometimes be related to fracture zones or reaction fronts.

420 Under hills characterized by relief of tens of meters in the South Carolina and Maryland

421 Piedmont, for example, the seismic low-velocity zone extends to tens of meters under

422 ridges but to shallower depths under valleys (St. Clair et al., 2015). This so-called bowtie

423 or pinched topography - deep low-velocity zones under hills combined with shallow

424 low-velocity zones under channels — was attributed by St. Clair et al. (2015) to opening

425 of fractures and to weathering under the hillform that occurred in the presence of the

426 compressive state of stress in the Piedmont.

427

428 More such geophysical surveys are needed to understand the reasons for such subsurface

429 properties. For example, water flow could be dominantly downward under ridges and

430 could drive net dissolution and mineral alteration, resulting in slower seismic velocities.

431 Minerals generally dissolve in downflowing water along flowlines as long as reactants

432 have not been $100 \%$ consumed. In high-relief valley-ridge systems, dissolution and 
433 water flow could occur even deeper than the elevation of the nearby channel, resulting in

434 a pinched topography such as that observed by St. Clair et al. (2015). Indeed, once acids

435 and oxidants are consumed, minerals can precipitate or re-crystallize. Thus, as the water

436 flows upward from beneath the ridge into the valley, it could drive net mineral

437 precipitation in relatively unaltered bedrock, resulting in faster seismic velocities under

438 the valley in some cases. In addition, if carbon dioxide degasses during upflow, it can

439 raise $\mathrm{pH}$ and cause mineral precipitation (Brantley et al., 2013a). Such flow patterns

440 have been discussed in the literature (Tóth, 1970).

441

442 In the next sections, we explore such ideas about reaction fronts, water flowlines, and

443 their implications. We emphasize reaction fronts under convex-upward hillslopes

444 developed on a single lithology near the upper parts of catchments where the fronts are

445 likely to be nested, mimicking surface topography. Thus our discussion does not treat

446 pinched topographies where weathering may occur deeper under the ridge than under the

447 nearby channel. Our discussion focusses on a sequence of reactions that can create

448 identifiable layers in regolith under a ridge: the profile-initiating reaction, the major

449 porosity-initiating reaction, and the soil-initiating reaction.

450

451 4.2. The profile-initiating reaction: oxidation or acid neutralization

452 As rock material advects upward under a hill, it begins to weather as its mineral surfaces

453 interact with water and atmospheric gases. We use the term profile-initiating mineral for

454 the most soluble mineral that first weathers at depth in the protolith to form weathered

455 rock (Brantley and White, 2009). In Fig. 1, the difference between the depth where the 
456 profile-initiating mineral first reacts under the hillcrest and the elevation of the associated

457 channel is noted as $\Delta B_{2}$. Thus, the relief of the protolith surface is noted as $\Delta B_{2}$ (Fig. 1).

459 This deepest reaction is often an oxidation reaction, especially in quartzo-feldspathic

460 rocks. This is because $\mathrm{O}_{2}$ generally is not consumed as fast as $\mathrm{CO}_{2}$ during reaction of a

461 felsic rock. For example, Brantley et al. (2013b) observed that oxidation was the deepest

462 reaction in a felsic Fe-poor rock in the Virginia Piedmont, but that acid-driven dissolution

463 occurred at greater depths on a nearby mafic, Fe-rich rock.

465 The effect of rock composition on $\mathrm{O}_{2}$ and $\mathrm{CO}_{2}$ consumption is related to the ratio, $R^{o}$, of

$466 \mathrm{O}_{2}$-consuming oxides to $\mathrm{CO}_{2}$-consuming base cation oxides in the rock. The ratio $R^{o}$ can

467 be calculated (Holland and Zbinden, 1988; Feakes et al., 1989) using the expression,

$468 R^{o}=M_{\mathrm{FeO}}^{o} /\left(8\left(M_{\mathrm{Na}_{2} \mathrm{O}}^{o}+M_{K_{2} \mathrm{O}}^{o}+M_{\mathrm{MgO} \mathrm{O}}^{o}+M_{\mathrm{CaO}}^{o}\right)\right)$. Here, FeO is assumed to be the dominant

469 redox-active oxide and $M_{\text {oxide }}^{o}$ is the moles oxide per kilogram protolith. Reaction

470 stoichiometry dictates that 0.25 moles of $\mathrm{O}_{2}$ are consumed per mole of reacted $\mathrm{FeO}$ and 2

471 moles of $\mathrm{CO}_{2}$ per mole of solubilized base cation oxide. The $R^{o}$ value, the capacity of the

472 protolith to consume oxygen ratioed to its capacity to consume acid, tends to be larger for

473 mafic rocks than felsic rocks. For example, the $R^{o}$ for a typical diabase (0.04) is larger

474 than for a granite (0.02) because diabase has a high content of Fe(II) compared to base

475 cation oxides. Thus, for some mole ratios of $\mathrm{CO}_{2}: \mathrm{O}_{2}$ in the soil atmosphere, a gas mixture

476 will become depleted in $\mathrm{O}_{2}$ on a mafic rock but not on a felsic rock. Consistent with this,

477 acid dissolution has been documented deeper on a diabase weathering in the VA

478 Piedmont than oxidation whereas the opposite was observed on a nearby granite 
479 (Bazilevskaya et al., 2013). Of course, the rock composition $\left(R^{o}\right)$ is only one part of the

480 control on the profile-initiating reaction: also of importance is the composition of the soil

481 atmosphere and the biotic controls on $\mathrm{O}_{2}$ consumption and $\mathrm{CO}_{2}$ generation in the soil

482 (Brantley et al., 2013b).

483

484 4.3. The importance of pyrite

485 The $R^{o}$ as described above is essentially a mass balance on mineral components in a rock

486 that consume $\mathrm{O}_{2}$ vs. $\mathrm{CO}_{2}$. To calculate the relative depths of oxidation and acid-driven

487 dissolution in a rock containing significant pyrite and carbonate, the $R^{o}$ as defined above

488 is inadequate. For rocks with sufficient pyrite and calcite, the formula for $R^{o}$ can be

489 modified (Feakes et al., 1989; Brantley et al., 2013a):

490

$R^{o}=\left(0.25 M_{\mathrm{FeO}}^{o}+3.75 M_{\mathrm{FeS} 2}^{o}\right) /\left(2\left(M_{\mathrm{Na}_{2} \mathrm{O}}^{o}+M_{\mathrm{K}_{2} \mathrm{O}}^{o}+M_{\mathrm{MgO} \mathrm{O}}^{o}+M_{\mathrm{CaO}}^{o}\right)+M_{\mathrm{CaO}(c)}^{o}\right)$. Here, $M_{\mathrm{CaO}(c))}^{o}$

491 and $M_{\mathrm{FeS} 2}^{o}$ are the moles of calcite and pyrite per kilogram of protolith, respectively.

492 This equation takes into account that one mole of pyrite $\left(\mathrm{FeS}_{2}\right)$ consumes 3.75 moles of

$493 \mathrm{O}_{2}$, and one mole of $\mathrm{CaCO}_{3}$ consumes one mole of $\mathrm{CO}_{2}$ during dissolution.

495 However, an important aspect of pyrite's reactivity that is not incorporated in $R^{o}$ is that

496 pyrite oxidation releases the strong mineral acid $\mathrm{H}_{2} \mathrm{SO}_{4}$. When pyrite is abundant,

497 therefore, the released sulfuric acid may dissolve minerals and cause significant

498 dissolution near the oxidation zone (Chigira and Oyama, 1999). Such $\mathrm{H}_{2} \mathrm{SO}_{4}$-driven

499 dissolution can be important at the pedon, watershed, and global scales (Lichtner and

500 Waber, 1992; Calmels et al., 2007; Torres et al., 2014). 
502 In some rocks with high pyrite content, enough $\mathrm{H}_{2} \mathrm{SO}_{4}$ can be generated to develop

503 significant permeability at depth (Ayraud et al., 2008). Zones of such high permeability

504 associated with pyrite oxidation are often found near the water table. This is likely

505 because the water table demarcates a gradient in $\mathrm{O}_{2}$ concentration dividing the vadose

506 zone, where gas migrates quickly, from the water-saturated phreatic zone, where gas

507 migrates slowly (Bornstein et al., 1980). However, pyrite is also sometimes observed to

508 have been oxidatively dissolved from rock materials recovered from beneath the water

509 table (Ayraud et al., 2008; Brantley et al., 2013a). Such oxidation may occur when

510 oxygenated fluids are transported beneath the water table (Sullivan et al., in press).

511 Another explanation could be that the water table was lower in the past. This may be

512 particularly applicable in mid-latitude North America, where the last 2000 years have

513 been substantially wetter than the previous 100,000 years (Shuman and Marsicek, 2016).

515 Pyrite may also oxidize beneath the water table because of oxidants other than oxygen.

516 For example, many bacteria associated with pyrite oxidation can use nitrate rather than

517 oxygen as the electron acceptor and nitrate is sometimes advected beneath the water table

518 (Ayraud et al., 2008). In addition, the $\mathrm{Fe}^{3+}$ that is released to solution by pyrite oxidation

519 can itself act as an oxidant (Nordstrom, 2000). Pyrite oxidation is thus autocatalytic

520 because it produces a product (aqueous $\mathrm{Fe}^{3+}$ ) that is also a reactant. Rocks rich in pyrite

521 therefore can develop zones of enhanced secondary permeability when an oxidant (e.g.,

$\left.522 \mathrm{O}_{2}, \mathrm{NO}_{3}^{-}, \mathrm{Fe}^{3+}\right)$ is available at high concentration.

523

524 4.4. Major porosity-initiating and soil-initiating reactions 
525 As rock material advects upward above the depth of the profile-initiating reaction where

526 the most soluble mineral reacts, the moderately soluble minerals eventually begin to

527 dissolve and create porosity and permeability. When this next reaction involves a more

528 abundant mineral such as feldspar that reacts isovolumetrically to create porosity, we

529 term the reaction the major porosity-initiating reaction. In some cases this front

530 demarcates formation of saprolite.

531

532 At an even higher elevation, $\Delta B_{1}$, above the nearest channel (Fig. 1), a soil-initiating

533 reaction demarcates the bottom of massive soil or soil. The soil-initiation reaction

534 generally involves another abundant mineral. Dissolution of this mineral causes further

535 disaggregation and clay formation in a zone of intense biological processing where

536 weathering eventually becomes nonisovolumetric. This soil-initiating mineral has lower

537 solubility than the major porosity- or profile-initiating minerals.

538

539 Notably, these reactions can cause large changes in porosity and permeability. For

540 example, the profile-initiating reaction may cause the transformation from bedrock to

541 weathered rock, the major porosity-initiating reaction may cause the transformation from

542 weathered rock to saprolite, or the soil-initiating reaction may cause the transformation

543 from saprolite to massive soil. In these cases the reactions may cause large enough

544 porosity and permeability changes that water flow paths transition from vertical to

545 horizontal (Balashov et al., 1999; Brantley et al., 2013b). Alternatively, some other

546 physical, hydrological, or biological mechanism may cause the transformation from

547 bedrock to weathered rock or weathered rock to saprolite or saprolite to soil; in such 
548 cases, the reactions may simply be co-located at the depths where that phenomenon is

549 important. Regardless, we argue that the elemental depth profiles can nonetheless yield

550 information about flow patterns and the cumulative flows of water, as explored in section

551 6. First, however, we summarize in the next section the three case examples showing

552 stacked reaction fronts from the mid-Atlantic region of the eastern USA. Evidence

553 suggests that these systems are evolving under or near steady state conditions (Pavich et

554 al., 1989; West et al., 2013).

555

556 5. Case studies

557 5.4.Virginia Piedmont diabase and granite

558 The first two cases are diabase and granitic rocks weathering at ridgetop positions in

559 Virginia (Pavich, 1986; Pavich et al., 1989; White et al., 2001). The two lithologies have

560 an initial porosity of about $2-3 \%$ and are eroding at rates that are equivalent within error

$561( \pm 30 \%): 4.5<E<13 \mathrm{~m} \mathrm{My}^{-1}$ (Pavich et al., 1985; Pavich et al., 1989; Price et al., 2008;

562 Portenga and Bierman, 2011; Bacon et al., 2012). The ridgetops have weathered to form

563 residual soils on bedrock in the Piedmont, a physiographic province characterized by low

564 relief ranging in elevation from 90 to 200 masl. The temperate climate is characterized by

565 a MAP of $\sim 1040 \mathrm{~mm} \mathrm{y}^{-1}$.

566

567 Hills in the Piedmont are close to geomorphological equilibrium given the long exposure

568 time and low erosion rates (Pavich et al., 1989). This is shown by data in Table S1

569 (supplementary information) which summarizes the averages for the slopes of hills in the

570 region on the different lithologies. The slopes in the table were approximated as $r / L$ for 
57110 hills on diabase and granite in the VA Piedmont. Here, $r$ is the relief of the hill and $L$

572 is the distance from hillcrest to the nearest channel head (Fig. 1). The values for the

573 slopes measured from the hillcrest down to the channel head are equal within error $(0.04$

$574 \pm 0.02$ vs. $0.05 \pm 0.01$, respectively), consistent with the similar erosion rates, as

575 discussed for Fig. 3 or Eq. 6 in section 3.

576

577 The diabase profile discussed here is from a borehole in the Late Triassic Manassas sill

578 complex (Smith et al., 1975). The rock contains about 3 vol. \% quartz, 54 vol. \%

579 plagioclase feldspar, and 36 vol. \% pyroxene (augite) with minor hornblende, ilmenite,

580 magnetite, pyrite, and occasional reports of trace biotite. In optical microscopy, the augite

581 shows ferrous-rich and -poor lamellae (Bazilevskaya et al., 2013; Bazilevskaya et al.,

582 2014). The regolith thickness at the ridgetop is $2 \mathrm{~m}$ (Fig. 2).

583

584 The granitic rock is a metamorphosed light-gray muscovite-biotite monzogranite

585 (Lonsdale, 1927; Drake and Froelich, 1977) belonging to the Cambro-Ordovician

586 Occoquan Formation. It contains about 41 vol. \% quartz, 52 vol. \% feldspar, and 7 vol.

$587 \%$ mica, including biotite and muscovite (Bazilevskaya et al., 2013). The protolith is a

588 two-feldspar granite (i.e., plagioclase and alkali feldspar) and includes trace zircon,

589 pyrite, and magnetite (White et al., 2001). The primary quartz and feldspar mineral

590 grains can exceed $6 \mathrm{~mm}$ (Lonsdale, 1927). The regolith thickness under the ridgetop,

591 measured down to protolith, is $\sim 22 \mathrm{~m}$ (Fig. 2).

592 
593 The diabase has a high $\mathrm{FeO}$ content compared to base cation oxides $\left(R^{o}=0.04\right)$; and

594 consistent with the discussion in the last section, the profile initiation reaction is acid-

595 promoted dissolution rather than oxidation. Specifically, the first reaction is dissolution

596 of Fe(II)-containing augitic pyroxene without precipitation of ferric oxide. Lamellae of

597 this composition in the pyroxene are observed under transmission electron microscopy to

598 have dissolved to a small extent in thin sections from $2 \mathrm{~m}$ depth in the weathered-rock

599 zone (Bazilevskaya et al., 2014). Such solubilization and removal of Fe typically occurs

600 in the absence of $\mathrm{O}_{2}$. Solubilization of this profile-initiating mineral, ferrous pyroxene,

601 has therefore been attributed to consumption of $\mathrm{O}_{2}$ higher in the rock consistent with the

602 high ferrous content (large $R^{o}$ value). Where $\mathrm{O}_{2}$ is still present higher in the profile

603 (above $\sim 1 \mathrm{~m}$ ), the $\mathrm{Fe}$ in the pyroxene was dissolved and reprecipitated as Fe oxide

604 (Bazilevskaya et al., 2013; Bazilevskaya et al., 2014). In addition, pyrite is generally

605 missing from the rock down to about $1.8 \mathrm{~m}$ depth.

606

607 In contrast, the deepest profile-initiating reactions in the ferrous iron-poor granite is 608 oxidation of biotite and oxidative dissolution of pyrite (Bazilevskaya et al., 2014). The

609 relatively thin oxidation depth interval is also marked by loss of $\mathrm{K}^{+}$. Biotite loses this

610 cation to maintain charge balance as $\mathrm{Fe}(\mathrm{II})$ is oxidized to $\mathrm{Fe}(\mathrm{III})$. Thus, we infer that $\mathrm{O}_{2}$

611 remains present at relatively high concentrations to significant depths on this lithology

612 (Brantley et al., 2013b; Navarre-Sitchler et al., 2015). Biotite and pyrite are oxidized at a

613 depth somewhere near $20 \mathrm{~m}$, defining the weathered/unweathered rock interface

614 (Bazilevskaya et al., 2013; Bazilevskaya et al., 2014).

615 
616 Above the profile-initiating reactions on the diabase (ferrous pyroxene dissolution) and

617 the granite (biotite oxidation), the next minerals to react are calcic pyroxene and

618 plagioclase feldspar, respectively. These reactions, which proceed to $100 \%$ completion,

619 mark the transformation of weathered rock to saprolite (Figs. 2A,B). The nature of these

620 major porosity-initiating reaction fronts are different in the two rocks, however. The

621 reaction front for calcic augite in the diabase (Fig. 2A) is only a few tens of centimeters

622 in thickness (Bazilevskaya et al., 2013; Brantley et al., 2013b; Bazilevskaya et al., 2014).

623 In contrast, the reaction front for plagioclase in the granite is much wider (9-10 m, Fig.

624 2B). Bazilevskaya et al. (2013) used model simulations to argue that the wider reaction

625 front for plagioclase on the granite was caused by a larger advection velocity of water

626 through the front compared to the pyroxene front on the diabase (see the wider fronts in

627 Fig. $3 \mathrm{E}$ vs. $3 \mathrm{H})$.

628

629 The final reactions on the two lithologies are the soil initiation reactions: dissolution of

630 plagioclase in the diabase and alkali-rich minerals in the granite. All these important

631 reactions in the diabase - the reaction fronts for profile initiation (ferrous pyroxene),

632 major porosity initiation (calcic pyroxene), and soil initiation (plagioclase) — are located

633 within centimeters of one another (Fig. 2B). In contrast, the alkali-rich minerals dissolve

634 in the upper $3 \mathrm{~m}$ of the granite, tens of meters above the deeper-dissolving plagioclase

635 (Fig. 2).

636

637 5.5. Rose Hill shale 
638 The third example is weathering of Rose Hill shale in the Valley and Ridge

639 Physiographic province in Pennsylvania in the Susquehanna Shale Hills Critical Zone

640 Observatory (Fig. 2). Based on isotopic measurements, the rate of erosion of the Shale

641 Hills catchment, $\sim 30 \mathrm{~m} / \mathrm{My}$, is several times greater than that of the rocks of the

642 Piedmont (West et al., 2014). Consistent with this higher erosion rate, the slope, $r / L$,

643 equals 0.19 for the Rose Hill shale, significantly higher than the shallow slopes exhibited

644 by the hills in the Piedmont on the more competent diabase and granite lithologies $(0.04$

645 to 0.05). This higher slope is consistent with Eq. (6) because of the faster erosion. At

646 Shale Hills, West et al. showed that the rate of erosive loss of soil is within error of the

647 rate of production of soil at the ridgetops. Therefore, like the Piedmont, the weathering

648 advance rate under the ridgetops is considered here to be roughly equal to the erosion

649 rate.

650

651 In the Rose Hill shale, pyrite oxidation and carbonate dissolution are the deepest

652 reactions inferred to occur beneath the ridge and it is difficult based on sample recovery

653 to determine which reaction occurs deeper (Brantley et al., 2013a). Pyrite is depleted to

654 depths of $23 \mathrm{~m}$ beneath the northern ridge, to $16 \mathrm{~m}$ beneath the southern ridge closer to

655 the outlet of the watershed, and to 8 or $9 \mathrm{~m}$ beneath the channel (Jin et al., 2011; Brantley

656 et al., 2013a; Sullivan et al., in press). Oxidation of the trace mineral pyrite comprises a

657 very thin $(<1 \mathrm{~m})$ reaction front (Fig. 2). Under the ridge, the pyrite front is coincident

658 with the zone of water table variation; but under the valley, the front is deeper than this

659 zone. Pyrite is assumed here to be the profile-initiating reaction in the shale.

660 
661 Partly because of acid released during pyrite oxidation and partly because of carbonic

662 acid, carbonate minerals have also dissolved to a depth of $\sim 23 \mathrm{~m}$ beneath the northern

663 ridge (Brantley et al., 2013a) and have a reaction front thickness $\leq 3 \mathrm{~m}$. Under the valley,

664 carbonate is depleted only to a depth of about $2 \mathrm{~m}$, roughly coincident with the water

665 table. Jin et al. (2011) called the carbonate-free material saprock because it maintains

666 much of the physical character of bedrock. For the shale, we define carbonate dissolution

667 as the major porosity-initiating reaction, although it did not disaggregate the rock into

668 saprolite and it may even initiate deeper than pyrite oxidation, perhaps because $\mathrm{H}_{2} \mathrm{SO}_{4}$

669 diffused downward.

670

671 Within the saprock near the pyrite and carbonate reaction fronts, oxidation of chlorite

672 also begins, releasing $\mathrm{Mg}$ to solution as the mineral transforms to vermiculite (Fig. 2C).

673 Under the ridge, this oxidation begins near the water table and continues upward. Under

674 the valley, this oxidation begins at $8-9 \mathrm{~m}$ depth. Very little change in physical character

675 of the saprock has been observed to correlate with chlorite oxidation other than

676 occasional microcracking.

677

678 Finally, in a heavily fractured zone of altered rock that characterizes the upper $\sim 6 \mathrm{~m}$

679 throughout the catchment, illite dissolution initiates and eventually disaggregates the rock

680 to form augerable soil. Illite dissolution is thus defined here as the soil-initiating reaction.

681 The fracture zone has been attributed to frost-related processes during the late Pleistocene

682 and Last Glacial Maximum (Jin et al., 2010b).

683 


\section{6. Depth, thickness, and spacing of reaction fronts at ridgetops}

685 As described in the last section, the depth, thickness, and spacing of many of the reaction

686 fronts were observed to be larger on the quartzo-feldspathic examples (granite, shale)

687 than on the mafic rock. Although the number of case studies is small, such patterns have

688 been noted elsewhere as well (Cleaves et al., 1970; Rice et al., 1985; Pavich et al., 1989;

689 Buol and Weed, 1991; Nesbitt and Markovics, 1997; White et al., 1998; White et al.,

690 2001; Anderson et al., 2002; White et al., 2002; Hausrath et al., 2011; Bazilevskaya et al.,

691 2013; Behrens et al., 2015; Navarre-Sitchler et al., 2015).

692

693 Bazilevskaya et al. (2013) explained the observation of thicker regolith on granitic as

694 opposed to mafic rocks by a four-fold argument related to the production of weathering-

695 induced fractures at the base of the weathering profile: (i) the profile-initiating reaction

696 tends to be oxidation rather than acid-promoted dissolution on felsic rocks because of the

697 low $R^{o}$; (ii) oxidation is often marked by an increase in volume that drives cracking (e.g.,

698 Fletcher et al., 2006); (iii) cracking promotes advective transport; and (iv) solute transport

699 by advection tends to thicken regolith (as well as widen reaction fronts) (Brantley and

700 Lebedeva, 2011). Biotite oxidation may be an especially important reaction in cracking

701 felsic rocks (Eggler et al., 1969; Van Tassel and Grant, 1980; Nesbitt and Markovics,

702 1997; Fletcher et al., 2006; Buss et al., 2008; Lachassagne et al., 2011). However,

703 reactions of minerals such as pyroxene have also been associated with cracking (Jamtveit

704 and Hammer, 2012; Behrens et al., 2015).

705 
706 The key point here is these oxidation reactions are like pyrite oxidation in that they are

707 autocatalytic: they produce a reaction product (in this case, newly cracked surface area)

708 that acts as a reactant that promotes further chemical reaction. Such autocatalysis thus

709 creates an environment that can drive continued fracturing and deeper weathering

710 penetration into protolith. In fact, subhorizontal fracture sets that are often tens of meters

711 in thickness and highly friable are observed in the upper meters of crystalline bedrock at

712 the base of many weathering profiles at depths to $100-200 \mathrm{~m}$, and some argue that these

713 fractures are caused by the weathering itself (Jones, 1985; Dewandel et al., 2006; Legout

714 et al., 2007; Lachassagne et al., 2011; Welch and Allen, 2014). Some researchers argue

715 that alternative drivers for fracturing such as tectonic activity or topographic readjustment

716 cannot explain many of the observations of such deep fractured zones on crystalline rock

717 (Lachassagne et al., 2011). These deep fissured zones have been described to sometimes

718 be roughly coincident with the water table or sometimes to lie well below the water table

719 (e.g. Jones, 1985). Examples of fissured rock layers in the literature are generally derived

720 from felsic rocks.

721

722 In addition to the formation of a fissured zone at the top of felsic bedrock under

723 weathering profiles, another reason for enhanced advection through reaction fronts on

724 felsic rocks is that the porosity of these rocks is propped open during weathering because

725 they have higher contents of quartz (Figs. 5, 6) and intergrowths of K-containing mica

726 and quartz (Pavich et al., 1989). Without quartz and K mica, regolith may be thinner on

727 mafic rocks. In addition, smectitic clays form more readily on mafic rocks because of the

728 high $\mathrm{Ca}$ and $\mathrm{Mg}$ content, and these clays can expand and plug porosity, restricting water 
729 influx (Rice et al., 1985; Pavich et al., 1989; Buol and Weed, 1991). We argue that these

730 tendencies all lead to thicker regolith and wider reaction fronts on quartzo-feldspathic as

731 compared to mafic rocks (when all else is held equal).

732

733 The final important observation from the case studies is that the reaction fronts are spaced

734 more widely in the felsic as compared to the mafic rocks (Fig. 2). Numerical models of

735 granitic weathering have been used to investigate such spacing (Moore et al., 2012;

736 Brantley et al., 2013b). Moore et al. concluded that the separation between the

737 plagioclase and potassium feldspar reaction fronts was larger in simulations that were

738 maintained unsaturated and open to $\mathrm{CO}_{2}$. In the presence of lower $\mathrm{pH}$ and high $\mathrm{CO}_{2}$

739 concentrations under unsaturated conditions, feldspar weathering was maintained far

740 from equilibrium, and reaction fronts for alkali and plagioclase feldspars became

741 separated. In addition, Brantley et al. (2013b) modelled the effect of $\mathrm{CO}_{2}$ and $\mathrm{O}_{2}$ on

742 weathering and concluded that lower $\mathrm{CO}_{2}$ and higher $\mathrm{O}_{2}$ in the soil atmosphere, such as

743 expected on a felsic rock with low $R^{o}$, results in separation of the acid and oxygen

744 consumption fronts, as observed on the Virginia granite (Fig. 2). In contrast, for a rock

745 like the diabase where the soil atmosphere evolves at depth to relatively high $\mathrm{CO}_{2}$ and

746 low $\mathrm{O}_{2}$, modelled fronts were observed to almost co-locate, as observed in the diabase

747 (Fig. 2).

748

749 7. Conceptual model for two-layer lateral flow inside hills

750 Although the L \& B model requires that water flows predominantly downward in the

751 unsaturated zone, water also flows laterally in hills (Pain and Ollier, 1996; Tague and 
752 Grant, 2004; Katsura et al., 2008). In hills developed on crystalline rocks, for example,

753 lateral water flow is especially common in the depth intervals of fluctuation of the water

754 table where chemical reactions are prevalent and where it is common to observe a highly

755 fractured and friable zone of weathered rock as described in the last section (Legout et

756 al., 2007; Ayraud et al., 2008). Biogeochemical reactions are localized in this zone

757 because (i) $\mathrm{O}_{2}$ and $\mathrm{CO}_{2}$ are entrained into the water as the water table fluctuates; (ii) $\mathrm{O}_{2}$

758 or other oxidants drive oxidation of minerals such as pyrite and biotite in this zone

759 (Taylor and Eggleton, 2001; Ayraud et al., 2008; Lachassagne et al., 2011), and (iii)

760 water chemistry changes rapidly and frequently, driving dissolution (Legout et al., 2007).

762 Lateral flow in hills is not always observed to be confined to the zone of the fluctuating

763 regional water table however. In fact, anywhere a high-permeability surface layer

764 overlies a low-permeability sublayer, water can flow laterally (e.g., Katsura et al., 2008)

765 as long as the permeability contrasts are about an order of magnitude (Hopp and

766 McDonnell, 2009). Such flow has been reported in shales, conglomerates, granites,

767 volcanics, schists, and other metasedimentary rocks (Cleaves et al., 1970; McDonnell,

768 1990; McGlynn and McDonnell, 2003; Peters et al., 2003; Tague and Grant, 2004;

769 Ayraud et al., 2008; Katsura et al., 2008; Graham et al., 2010; McGuire and McDonnell,

770 2010; van Meerveld et al., 2015; Sullivan et al., in press). 
772 Here the term interflow is used to refer to such lateral flow occurring high in a hill. This

773 term is used to differentiate it from lateral flow deeper within the hill, referred to here as

774 groundwater flow. Sometimes this interflow may be perched. In other cases, this high-

775 elevation lateral flow may occur because of a very high transient water table. Whether

776 interflow is perched or not, this lateral water flow is important in hills in addition to

777 lateral flow in another, deeper zone. In the well-studied Panola granite in Georgia

778 (USA), for example, a well-defined low-permeability layer located high in the hill allows

779 lateral flow of water to the channel at shallow depths after rain events; however, water

780 also flows laterally at a deeper boundary layer between weathered and unweathered rock

781 (van Meerveld et al., 2015). In crystalline felsic rocks such as the Panola granite, such a

782 deep zone of lateral flow is expected as described in the last section, because such

783 aquifers commonly have a high-permeability fissured and friable weathered rock layer

784 situated between the overlying saprolite and the underlying protolith (Jones, 1985). Here,

785 the upper flow is referred to as interflow and the lower flow as groundwater flow. We

786 argue that two such zones are likely where reaction fronts have separated over meters or

787 tens of meters, such as for the granite and shale in Fig. 2. In contrast, on massive mafic

788 rocks where reaction fronts do not separate, two zones of lateral flow are not likely to

789 develop (Fig. 2A).

790

791 We have not developed a numerical treatment of complete geochemical regolith

792 evolution in hills with vertical and lateral fluid flow. In Figs. 3-5, for example, the Darcy

793 velocities were held constant and vertical everywhere. However, because some 
794 simulations (see Fig. 3A) show that hills can have near-linear slopes, we instead explore

795 the flow patterns for a planar hillslope simply by considering what mass balance might

796 look like for a steady state (Fig. 7). The linear hill is assumed to be characterized by

797 reaction fronts that record fluid flows at that depth.

799 We start with a 1D conceptualization (Fig. 8). Net water flow downward creates the 800 upper reaction front $\left(\mathrm{RF}_{1}\right)$ defined as the soil-initiating reaction. This is also the location

801 of interflow. At greater depths, a second reaction delineates the major porosity-initiating

802 reaction $\left(\mathrm{RF}_{2}\right)$ and the location of groundwater flow. As we have discussed, for quartzo-

803 feldspathic rocks, $\mathrm{RF}_{2}$ is likely to be the oxidation front. $\mathrm{RF}_{1}$ is the front where $\mathrm{CO}_{2}$

804 consumption initiates and the organic acids are largely consumed. However, $\mathrm{CO}_{2}$ is also

805 consumed in reactions between $\mathrm{RF}_{1}$ and $\mathrm{RF}_{2}$. In the diagram, the bottom of each front is

806 labelled as $\mathrm{RF}_{1}$ or $\mathrm{RF}_{2}$ and the concentration of the reacting mineral is assumed to be

807 identical to that of protolith at that point.

808

809 Intermittently, a zone of water saturation occurs above $\mathrm{RF}_{1}$, varying up and down within

810 the hachured zone. This is the zone of occasional interflow and is labelled $Q_{i n t}$ and is

811 colored on Figs. 7 and 8. Likewise, $\mathrm{RF}_{2}$ marks the bottom of the major porosity-initiating

812 reaction and is often coincident with the interface between weathered rock and saprolite.

813 The lower colored zone sitting above $\mathrm{RF}_{2}$ shows the zone of variation in elevation of the 814 regional water table. This is the zone we term groundwater flow, $Q_{g w}$. 
816 For $Q_{i n t}$ at $\mathrm{RF}_{1}$ and $Q_{g w}$ at $\mathrm{RF}_{2}$, the thickness of the flow zones $\left(H_{i n t}\right.$ and $H_{g w}$ respectively;

817 Fig. 7) are assumed to be coincident with the thickness of the variations of the water table

818 for interflow and groundwater flow, respectively. These depth intervals are considered to

819 be zones of marked contrast in permeability that are caused in at least some cases by the

820 biogeochemical reactions. In the zones of water table variation, lateral flow occurs,

821 biogeochemical reactions are relatively fast, removal of material is relatively fast, and the

822 extent of weathering is high. The upper reaction front may also sometimes overlie a zone

823 of intense precipitation or illuviation of clay minerals that occlude permeability.

824

825 In contrast to the lateral flow zones, in the depth intervals well above $\mathrm{RF}_{1}$ and between

$826 \mathrm{RF}_{1}$ and $\mathrm{RF}_{2}$, water flows predominantly downward as $Q^{(0)}$ and $Q^{(1)}$, respectively (Fig.

827 8). We know this flow occurs because of the evidence of chemical reactions in this zone

828 and because such reaction can only occur if water is allowed to flow. Specifically, above

$829 \mathrm{RF}_{1}$ in Shale Hills or in the VA granite, potassium-containing minerals have dissolved

830 and their depletion documents the cumulative passage of water. Likewise, between $\mathrm{RF}_{1}$

831 and $\mathrm{RF}_{2}$, chlorite has oxidized and plagioclase has become depleted in Shale Hills and the

832 VA granite, respectively. The relatively wide reaction fronts above $\mathrm{RF}_{1}$ and $\mathrm{RF}_{2}$ for

833 calcite, chlorite, and plagioclase in Figs. 2B,C in the shale and the granite (Fig. 2)

834 document flow through the reaction front. Advective transport of solutes through a front

835 causes front widening (Bazilevskaya et al., 2013).

836

837 7.1. The mass balance equations for a linear hill model 
838 Figs. 1 and 8 delineate three important interfaces: land surface, $\mathrm{RF}_{1}$, and $\mathrm{RF}_{2}$. Between

839 these interfaces are important zones of regolith: (i) above $\mathrm{RF}_{1}$ : massive soil + soil

840 characterized by partial, intermittent water saturation, (ii) between $\mathrm{RF}_{1}$ and $\mathrm{RF}_{2}$ : saprolite

841 and weathered rock characterized by partial, intermittent water saturation; and (iii)

842 beneath $\mathrm{RF}_{2}$ : unweathered rock characterized by continual water saturation. In this

843 section, we seek to use element depth concentrations to predict the ratio of interflow to

844 groundwater flow, $Q_{\text {int }} / Q_{g w}$, for hills evolving such that $E=W$ (Figs. 7, 8).

845

846 The ratio $Q_{\text {int }} / Q_{g w}$ can be determined through water mass balance:

847

848

$$
Q_{p}=q_{p} A_{R}=Q^{(0)}=Q_{\mathrm{int}}+Q_{g w}
$$

$$
Q_{g w}=Q^{(1)}
$$

850

851 Here $q_{p}\left(\mathrm{~m} \mathrm{~s}^{-1}\right)$ is the net infiltration flux (roughly, mean annual precipitation (MAP)

852 minus evapotranspiration (ET)), and $A_{R}\left(\mathrm{~m}^{2}\right)$ as the map-view area. The downslope fluxes 853 can be written as (Fig. 7):

854

$$
Q_{i}=q_{i} a_{i}
$$

857 where $q_{i}$ is the Darcy velocity $\left(\mathrm{L} \mathrm{T}^{-1}\right.$ ) in each layer $i$ (where $i$ refers to subscript int or $858 g w$, respectively), and $a_{i}$ is the cross-sectional area of the layer of flow to the channel. 859 
860 In the upper layer $(i=i n t)$, we assume that reactive mineral 1 dissolves to release solute

861 1. Concentration of solute 1 at the bottom of the reaction front (at $\mathrm{RF}_{1}$ on Figs. 7,8 ) is

862 assumed to equal the equilibrium concentration $C_{1}^{e}\left(\mathrm{~kg} \mathrm{~m}^{-3}\right)$. Here, concentrations are

863 calculated per unit volume of pore fluid. Likewise, a second solute, component 2, is

864 present at equilibrium concentration $C_{2}^{e}$ at $\mathrm{RF}_{2}$.

865

866 The concentrations of components 1 and 2 in the solid phase are defined at $\mathrm{RF}_{1}$ and $\mathrm{RF}_{2}$

867 per unit volume of rock: $\rho_{1}$ and $\rho_{2}\left(\mathrm{~kg} \mathrm{~m}^{-3}\right)$, respectively. If the hill achieves a steady

868 state, then the weathering advance rate $\left(\mathrm{L} \mathrm{T}^{-1}\right), W$, can be equated for $\mathrm{RF}_{1}$ and $\mathrm{RF}_{2}$ :

869

870

$$
A_{R} W \Delta \rho_{1}^{(1)}=C_{1}^{a v} Q_{\mathrm{int}}+C_{1}^{e} Q^{(1)}=C_{1}^{a v} Q_{\mathrm{int}}+C_{1}^{e} Q_{g w}
$$

871

872

$$
A_{R} W \Delta \rho_{2}^{(2)}=C_{2}^{a v} Q_{g w}
$$

873

874 Here, $\Delta \rho_{i}^{(j)}$ is loss of the $i$ th component from the solid phase at $\mathrm{RF}_{1}$ or $\mathrm{RF}_{2}(j=1$ or 2 ,

875 respectively), and $C_{i}^{a v}$ is the concentration of component $i$ in the fluid averaged over the

876 cross section of the subhorizontal layer $j$. These equations express that the mass loss of

877 each component from the solid phase is balanced by solute transport in $Q_{i n t}$ and $Q_{g w}$.

878 Solutes 1 and 2 are furthermore assumed to be present in insignificant concentrations in

879 precipitation (or, alternately, the concentrations are corrected for inputs from

880 precipitation). For simplicity in Eqs. (9 A,B) we assume $C_{1}^{a v}=C_{1}^{e}$ and $C_{2}^{a v}=C_{2}^{e}$. In other

881 words, on average the flow removes water in equilibrium with the dissolving minerals. 
883 One complication is that components sometimes move in the subsurface not only as 884 solutes but also as particulates (Jin et al., 2010a; Sullivan et al., in press). To account for 885 this, we write $C_{1}^{a v}=C_{1}^{e}+C_{1}^{p r t}=\alpha C_{1}^{e}$. Here, $C_{1}^{p r t}$ is the concentration of component 1

886 moving as a particle and $\alpha \geq 1$ is the correction factor that corrects the equilibrium 887 concentration to take into account this particle transport. Using these assumptions Eqs.

888 (9a) and (9b) are rewritten as:

889

890

$$
\begin{aligned}
& A_{R} W \Delta \rho_{1}^{(1)}=C_{1}^{e}\left(\alpha Q_{\mathrm{int}}+Q_{g w}\right) \\
& A_{R} W \Delta \rho_{2}^{(2)}=C_{2}^{e} Q_{g w}
\end{aligned}
$$

892 This second equation emphasizes that $Q_{g w} / A_{R}$ (the watershed area-normalized flux of 893 groundwater out of the system) is an emergent property in the steady state hill: it is a 894 function of the erosion rate which is in turn set by the uplift rate (i.e., steady state 895 weathering rate where $E=W$ ). It is also affected by lithology through $\Delta \rho_{2}^{(2)}$, and mineral 896 solubility $\left(C_{2}^{e}\right)$. Although derived differently for somewhat different treatments, these

897 equations are equivalent to equations used previously (Cleaves et al., 1970; Pavich, 1986;

898 Cleaves, 1993; White, 2008; Brantley and White, 2009). However, interflow was not 899 taken explicitly into account in the previous work. 900

901 Our treatment emphasizes that the most soluble mineral is removed largely at $\mathrm{RF}_{2}$ while 902 the more moderately soluble rock-forming mineral is removed at $\mathrm{RF}_{1}$ and the least 903 soluble mineral is removed at the land surface. In effect, we argue that the hill evolves to 
904 remove minerals of different solubilities at different surfaces by partitioning water into

905 vertical and horizontal flow paths. Minerals can have solubilities that differ by small

906 numerical factors (e.g., different compositions of feldspar) or by orders of magnitude

907 (e.g., quartz and calcite). For example, the solubility of albite, which often defines $\mathrm{RF}_{2}$ in

908 granite, is approximately $6 \times 10^{-7} \mathrm{~mol} \mathrm{~L}^{-1}$ and the solubility of potassium feldspar, which

909 often defines $\mathrm{RF}_{1}$, is $3 \times 10^{-7} \mathrm{~mol} \mathrm{~L}^{-1}$. In contrast, the solubility of calcite is on the order

910 of $6 \times 10^{-5} \mathrm{~mol} \mathrm{~L}^{-1}$ (Berner, 1981). Small or large differences in solubility must be

911 accommodated by differences in cumulative flow if a hill evolves toward the steady state

912 condition of $E=W$.

913

914 Also notable, the soil-initiating reactions on the more felsic rocks in Fig. 2 are all

915 potassium-containing reactions. This is at least partly because the solubility of K-

916 containing silicates tends to be lower than that of the $\mathrm{Na}-, \mathrm{Mg}-$, and $\mathrm{Ca}-$ containing

917 silicates (Berner, 1981). However, $\mathrm{K}$ is also a nutrient that is taken up into biota, stored

918 for short residence times, then returned to the soil during plant degradation (Jobbagy and

919 Jackson, 2001). This internal recycling increases the aqueous K concentration in upper

920 regolith, decreasing the reactivity of $\mathrm{K}$ minerals. In this sense, biota comprise a negative

921 feedback on the K-containing minerals, slowing the rate of loss of K and Si from the top

922 layers because of the retention of K. Likewise, biota are largely responsible for

923 production of $\mathrm{CO}_{2}$, and higher values of $\mathrm{P}_{\mathrm{CO} 2}$ in the soil atmosphere result in greater

924 separation of the plagioclase and potassium feldspar reaction fronts (Moore et al., 2012).

925 
926 Equation (10) constrains the ratio we seek (where the approximation is true when particle

927 transport is insignificant):

928

$$
\frac{Q_{\mathrm{int}}}{Q_{g w}} \approx \frac{\Delta \rho_{1}^{(1)}}{\Delta \rho_{2}^{(2)}} \frac{C_{2}^{e}}{C_{1}^{e}}-1
$$

930

931 When $\alpha=1$ (i.e., for coarse-grained rocks that do not lose particles in the subsurface),

932 Eqs. (7)-(11) can be combined to yield:

933

934

$$
\frac{Q_{g w}}{Q_{p}}=\frac{\Delta \rho_{2}^{(2)} C_{1}^{e}}{\Delta \rho_{1}^{(1)} C^{e}}
$$

935

936 or, alternately,

937

938

$$
E=W=\frac{q_{p} C_{1}^{e}}{\Delta \rho_{1}^{(1)}}=\frac{Q_{g w} C^{e}}{A_{R} \Delta \rho_{2}^{(2)}} .
$$

939

940 These equations document that $Q_{i n t} / Q_{g w}$ is constrained by the loss of the major porosity-

941 and soil-initiating minerals and their solubilities. In the next sections we show that this

942 treatment roughly describes the three case studies.

943

944 7.2. Linear hill model applied to VA granite

945 We first apply Eqs. (10)-(13) to the VA granite (Bazilevskaya et al., 2013) using

946 estimates of MAP $-\mathrm{ET}=q_{p}=0.38 \mathrm{~m} \mathrm{y}^{-1}$ and $A_{R}=1.1 \mathrm{~km}^{2}$ for the Davis Run watershed 
947 in VA (Pavich et al., 1989). The volume change (strain) during weathering was taken

948 into account (Brimhall and Dietrich, 1987) because strain influences the mineral

949 concentrations when they are expressed per bulk volume of rock (see supplemental

950 information).

951

952 The granite weathering profile initiates with oxidation of biotite (to form weathered

953 rock), but the major increase in porosity is associated with dissolution of plagioclase to

954 form saprolite (Bazilevskaya et al., 2013). The major porosity-initiating reaction, $\mathrm{RF}_{2}$,

955 therefore occurs at the weathered rock/saprolite interface. We therefore assumed that

$956 \Delta \rho_{2}^{(2)}=1.017 \mathrm{kmol} \mathrm{Na}_{2} \mathrm{O} \mathrm{m}^{-3}$ (Table S2). Significant mass loss also occurs at $\mathrm{RF}_{1}$, the

957 soil-initiating reaction (at the saprolite/massive soil interface) because of dissolution of

958 the potassium-containing minerals (potassium feldspar, muscovite, and biotite; Table S2).

959 Therefore, $\Delta \rho_{1}^{(1)}=0.435 \mathrm{~K}_{2} \mathrm{O} \mathrm{kmol} \mathrm{m}{ }^{-3}$. We assumed that $Q_{\text {int }}$ flows at the massive soil /

960 saprolite interface and that $Q_{g w}$ flows at the saprolite / weathered rock interface.

961

962 Using Eq. (13) and $E=6 \mathrm{~m} \mathrm{My}^{-1}$, we calculate $C_{1}^{e}\left(=14.4 \mathrm{mmol} \mathrm{K} \mathrm{m}^{-3}\right)$. This value is

963 not unreasonable in comparison to measured values of the maximum dissolved

964 concentrations of potassium $\left(58.8 \mathrm{mmol} \mathrm{K} \mathrm{m}^{-3}\right)$ shown in Table $\mathrm{S} 3$ for a stream, Davis

965 Run, sampled on the VA granite (Pavich, 1986). To estimate $C_{2}^{e}$, we use the average

966 concentration of $\mathrm{Na}$ in Davis Run (Table S4, $261 \mathrm{mmol} \mathrm{Na} \mathrm{m}^{-3}$ ) which we assumed was a

967 good estimator for groundwater as it is likely to reflect baseflow (Pavich, 1986). These

968 values substituted into Eq. (11) yield $Q_{i n} / Q_{g w}=0.9$ (assuming no contribution from

969 particulates, i.e., $\alpha=1$ ). This rough estimate is not dissimilar to the value of 0.67 
970 estimated by Pavich (1986). Furthermore, if significant road salt contributes Na to the

971 stream as suggested by Pavich et al. (1986), the actual value of $C_{2}^{e}$ would be lower and

972 would yield a lower ratio of $Q_{i n} / Q_{g w}$. Using $Q_{p}=4.2 \times 10^{5} \mathrm{~m}^{3} \mathrm{y}^{-1}$ as reported for the

973 Virginia site and $Q_{i n t} / Q_{g w}=0.9$, we also estimate $Q_{g w} / A_{R}=0.20 \mathrm{~m} \mathrm{y}^{-1}$ and $Q_{\text {int }} / A_{R}=$

$9740.18 \mathrm{~m} \mathrm{y}^{-1}$.

975

976 7.3. Linear hill model applied to VA diabase

977 We complete the same calculations using Eqs. (10)-(13) for the weathering diabase,

978 although in this case it is difficult to distinguish groundwater flow (moving at the

979 weathered rock / saprolite interface) from interflow (moving at the saprolite / massive

980 soil interface) because the plagioclase $\left(\mathrm{RF}_{1}\right)$ and pyroxene $\left(\mathrm{RF}_{2}\right)$ reaction fronts do not

981 separate significantly (Fig. 2). After calculating and correcting for strain (supplemental

982 information), the loss of $\mathrm{Na}_{2} \mathrm{O}$ at the saprolite/soil interface $\left(\mathrm{RF}_{1}\right)$ was used to define loss

983 of plagioclase, $\Delta \rho_{1}^{(1)}=1686 \mathrm{Na}_{2} \mathrm{O} / 2 \mathrm{~mol} \mathrm{~m}^{-3}$, while the loss of $\mathrm{CaO}$ at the weathered rock

984 / saprolite interface $\left(\mathrm{RF}_{2}\right)$ was used to define loss of pyroxene, $\Delta \rho_{2}^{(2)}=1097 \mathrm{CaO} \mathrm{mol} \mathrm{m}^{-3}$

985 (Table S5).

986

987 Following the approach described above for the VA granite and using Eq. (13) with the

988 same values of $E\left(=6 \mathrm{~m} \mathrm{My}^{-1}\right)$ and $q_{p}\left(=0.38 \mathrm{~m} \mathrm{year}^{-1}\right), C_{1}^{e}$ was estimated to equal 0.027

$989 \mathrm{~mol} \mathrm{Na} \mathrm{m}^{-3}$ (Eq. (13)). An estimate for $C_{2}^{e}$ was derived from porewater Ca measured for

990 the 0.1 to $2.1 \mathrm{~m}$ depth interval for a diabase weathering in Pennsylvania (Yesavage et al., 
991 2016): $\sim 0.23 \mathrm{~mol} \mathrm{Ca} \mathrm{m}^{-3}$ (Table S6). With this value of $C_{2}^{e}$, Eq. (11) yields $Q_{\text {int }} / Q_{g w} \approx$

$992 \quad 12.1$.

993

994 Although these concentrations are all poorly constrained, $Q_{i n t} / Q_{g w}$ is a high value because

995 of the nature of diabase: loss of the oxide component from the massive soil-initiating

996 mineral is larger at $\mathrm{RF}_{1}$ than loss of the oxide component from the major-porosity

997 initiating mineral at $\mathrm{RF}_{2}$ because $\frac{\Delta \rho_{1}^{(1)}}{\Delta \rho_{2}^{(2)}}>1$. When this condition is met, it is likely from

998 Eq. 11 that $Q_{i n t} / Q_{g w}>1$ since $\frac{C_{2}^{e}}{C_{1}^{e}}>1$ (the mineral dissolving at $\mathrm{RF}_{1}$ is by definition less

999 soluble than the mineral at $\mathrm{RF}_{2}$.) At the most simple level, the condition $\frac{\Delta \rho_{1}^{(1)}}{\Delta \rho_{2}^{(2)}}>1$ is

1000 likely for the diabase because the rock has more plagioclase (dissolves at $\mathrm{RF}_{1}$ ) than

1001 pyroxene (dissolves at $\mathrm{RF}_{2}$ ). In contrast, for the granite, $\frac{\Delta \rho_{1}^{(1)}}{\Delta \rho_{2}^{(2)}}<1$ because this two-

1002 feldspar granite has more plagioclase $\left(\mathrm{RF}_{2}\right)$ than potassium feldspar $\left(\mathrm{RF}_{1}\right)$.

1003

1004 Also notable, although $\frac{C_{2}^{e}}{C_{1}^{e}}>1$ for $2=\mathrm{Na}$ and $1=\mathrm{K}$ simply because the plagioclase

1005 feldspars have higher solubilities than the alkali feldspars, vegetation also affects the ratio

$1006 \frac{C_{2}^{e}}{C_{1}^{e}}$ by working to retain nutrients in the upper layers. This in turn is likely to increase the

1007 concentration of $\mathrm{K}$ and decrease $\frac{C_{2}^{e}}{C_{1}^{e}}$ compared to an abiotic analogue, affecting $Q_{i n t} / Q_{g w . .}$ 
1008 In effect, vegetation retains and recycles $\mathrm{K}$ in the upper layers (Brantley et al., 2012),

1009 stabilizing K-containing minerals by increasing aqueous $\mathrm{K}$ concentrations. On the other

1010 hand, vegetation also returns water to the atmosphere through evapotranspiration, a

1011 process which decreases $Q_{i n t}$ and $Q_{g w}$. Overall, vegetation is therefore likely to shunt less

1012 water to interflow. (Brantley et al., 2012)

1013

1014 7.4. Linear hill model applied to Shale Hills

1015 We also use Eq. (11) for Shale Hills where the major porosity-initiating mineral is

1016 assumed to be ankeritic calcite $\left(\mathrm{RF}_{2}\right)$ and the soil-initiating mineral is illite $\left(\mathrm{RF}_{1}\right)$. The

1017 ankerite and illite losses at $\mathrm{RF}_{2}$ and $\mathrm{RF}_{1}$ yield $\Delta \rho_{2}^{(2)}=215$ and $\Delta \rho_{1}^{(1)}=579 \mathrm{~kg} \mathrm{~m}^{-3}$ of

1018 bedrock (Table S7). The shale is thus more similar to the diabase than the granite in that

$1019 \frac{\Delta \rho_{1}^{(1)}}{\Delta \rho_{2}^{(2)}}>1$. In this case where we have ample field data, estimates for the solute

1020 concentrations were derived from groundwater measurements: $C_{1}^{e}=0.0133 \mathrm{~g} / \mathrm{L}$ of illite

1021 and $C_{2}^{e}=0.15 \mathrm{~g} / \mathrm{L}$ of $\left(\mathrm{Ca}_{0.8} \mathrm{Mg}_{0.2}\right) \mathrm{CO}_{3}$. However, more than half of the total clay

1022 removed is removed in the subsurface as particulates (Sullivan et al., in press): we

1023 therefore set $\alpha=2.5$. Inserting these values into Eq. (11) yields $Q_{i n} / Q_{g w}=12$. This value

1024 is very similar to $Q_{i n} / Q_{g w}$ estimated based on hydraulic conductivities by Sullivan et al.

1025 (submitted): $\sim 10$.

1026

1027 In this case, because we did not use $E$ to calculate $C_{1}^{e}$ from Eq. (13), we instead use Eqs

1028 (10) and (7) to calculate $Q_{g w}$ and $Q_{i n t}$. We used the average erosion rate (assumed equal

1029 to the weathering advance rate, $W$ ) for Shale Hills of $30 \mathrm{~m} / \mathrm{My}$ (West et al., 2014) and 
1030 the watershed surface area $\left(A_{R}\right)$ of $0.08 \mathrm{~km}^{2}$. Eq. (10b) yields $Q_{g w}=3 \times 10^{3} \mathrm{~m}^{3} \mathrm{y}^{-1}$. This

1031 value agrees with published estimates estimated for groundwater outflow by other means

1032 at Shale Hills $\left(3 \times 10^{3} \mathrm{~m}^{3} \mathrm{y}^{-1}\right)$ by Lin et al. (2006).

1033

\section{8. Lithology and $Q_{i n t} / Q_{g w}$}

1035 These examples are order-of-magnitude estimates that were discussed to show that the 1036 linear hill mass balance is a useful representation for some systems. In fact, the ratio of

$1037 Q_{i n t}$ to $Q_{g w}$ might be possible to estimate even for poorly defined systems just on the basis

1038 of rock composition alone. This would address the need for better conceptual models for

1039 groundwater systems as articulated in the literature (Banks et al., 2009; MacQuarrie et al., 1040 2010).

1041

1042 As an example, we calculate $Q_{i n} / Q_{g w}$ for another felsic system in the Piedmont where we 1043 have even less information: Pond Branch, a watershed developed on a metapelite

1044 (Cleaves et al., 1970). No concentration vs. depth data were reported; however, the initial 1045 metapelite has $\sim 10.6 \%$ plagioclase, $23.9 \%$ muscovite, and $9.8 \%$ biotite (Cleaves et al.,

1046 1970). The main dissolution reactions are observed to be weathering of $\mathrm{Na}$ and $\mathrm{Ca}-$

1047 containing plagioclase and K-containing mica (Cleaves et al., 1970; Pavich et al., 1989).

1048

1049 Applying the linear hill calculations (Eqs. 10-13) to Pond Branch, we choose $\mathrm{Na}$ and $\mathrm{K}$ as 1050 components 2 and 1 respectively. Dissolution of plagioclase (with composition of $22 \%$

1051 anorthite) is assumed to initiate at $\mathrm{RF}_{2}$ (component $2=\mathrm{Na}, \Delta \rho_{2}^{(2)} \approx 825$ mole Na per $\mathrm{m}^{3}$

1052 of rock) and biotite at $\mathrm{RF}_{1}$ (component $1=\mathrm{K}, \Delta \rho_{1}^{(1)} \approx 670$ mole $\mathrm{K}$ per $\mathrm{m}^{3}$ ). With the 
1053 reported values of $1.9 \mathrm{ppm} \mathrm{K}\left(0.049 \mathrm{~mol} \mathrm{~m}^{-3}\right)$ in interflow and $1.5 \mathrm{ppm} \mathrm{Na}(0.065 \mathrm{~mol}$

$1054 \mathrm{~m}^{-3}$ ) in baseflow (Cleaves et al., 1970), and (MAP $\left.-\mathrm{ET}\right)=0.18 \mathrm{~m} \mathrm{y}^{-1}$ (Cleaves et al.,

1055 1970), we calculate $Q_{\text {int }} / A_{R}=0.013 \mathrm{~m} \mathrm{y}^{-1}, Q_{g w} / A_{R}=0.167 \mathrm{~m} \mathrm{y}^{-1}$, and $Q_{\text {int }} / Q_{g w} \approx 0.08$.

1056

1057 Assuming that water leaves the catchment either as baseflow or interflow, and equating

1058 baseflow to groundwater flow, this value of $Q_{i n} t Q_{g w}$ is consistent with loss of $92 \%$ of

1059 water that enters the catchment as groundwater. This value is in turn surprisingly

1060 consistent with the published estimate $\left(Q_{i n t} / Q_{g w} \approx 0.1\right)$ that $90 \%$ of the water left the

1061 catchment as baseflow (Cleaves et al., 1970). Instead of relying on observations from

1062 stream chemistry, we could have calculated $Q_{i n t} / Q_{g w}$ from estimated solubilities for albite

$1063\left(6 \times 10^{-4} \mathrm{~mol} \mathrm{~m}^{-3}\right)$ and potassium feldspar $\left(3 \times 10^{-4} \mathrm{~mol} \mathrm{~m}^{-3}\right)$ in pure water (Berner, 1981).

1064 In this case the estimate is $Q_{i n} / Q_{g w} \approx 0.7$, consistent again with most of the water ( $\left.60 \%\right)$

1065 leaving as groundwater flow.

1066

1067 Thus even for systems without mineral depth profiles or stream chemistry observations,

1068 the approach has utility. Patterns of $Q_{i n t} / Q_{g w}$ for steady state systems might therefore be

1069 predictable from lithology: from Eq. (11) we predict that $Q_{i n} / Q_{g w}$ should be largest for

1070 protoliths with a trace amount of a highly soluble mineral in a mostly insoluble and

1071 impermeable matrix, i.e, high values of $C_{2}^{e} / C_{1}^{e}$ and $\Delta \rho_{1}^{(1)} / \Delta \rho_{2}^{(2)}$ respectively. This

1072 describes, for example, a low-permeability quartz-dominated sandstone with minor

1073 calcite and alkali feldspar. In this case, component 1 is potassium present in relatively

1074 insoluble alkali feldspar and 2 is $\mathrm{CaCO}_{3}$ present in trace quantities as the soluble mineral

1075 calcite. Assuming solubilities in pure water of potassium feldspar and calcite of $3 \times 10^{-4}$ 
1076 and $0.06 \mathrm{~mol} \mathrm{~m}^{-3}$, respectively (Berner, 1981), yields $Q_{i n t} / Q_{g w} \gg 1$. In this case, Eq. (12)

1077 is consistent with $0.5 \%$ of the meteoric influx leaving as groundwater flow from a low-

1078 permeability sandstone that contains $5 \%$ calcite (major porosity-initiating mineral) and

$10795 \%$ potassium feldspar (soil-initiating mineral).

1080

1081 These ideas can also be applied to igneous rocks ranging from felsic to mafic

1082 compositions. This gradient varies from granites that contain abundant quartz, both types

1083 of feldspars (alkali feldspars with potassium and plagioclase feldspars with

1084 sodium/calcium), and micas; to diorites with plagioclase feldspar, minor quartz, mica,

1085 and amphibole; to diabase (gabbroic rocks) with mainly plagioclase and pyroxene.

1086 Regardless of the mineralogy, $C_{1}^{e}<C_{2}^{e}$ because mineral 2 dissolves at depth and mineral

10871 dissolves near the surface. To estimate a first-order approximation using Eq. (11), we

1088 therefore only consider $\Delta \rho_{1}^{(1)} / \Delta \rho_{2}^{(2)}$. In a granite where $\Delta \rho_{1}^{(1)} / \Delta \rho_{2}^{(2)}<1$ (1 refers to

1089 potassium minerals alkali feldspar + mica; 2 refers to plagioclase), the value of $Q_{i n} / Q_{g w}$

1090 from Eq. (11) is < 1 and most water leaves the hill as groundwater. In contrast, in a mafic

1091 rock (mineral $1=$ plagioclase and $2=$ pyroxene) such as the VA diabase discussed here,

$1092 \Delta \rho_{1}^{(1)} / \Delta \rho_{2}^{(2)}>1$. Therefore, according to Eq. (11), more water leaves that rock as

1093 interflow than as groundwater.

1094

1095 With these calculations we are implying that groundwater will be greater than interflow

1096 at steady state in some hills simply because of the mineralogical composition. In effect,

1097 when a deep-reacting mineral is more abundant than a shallow-reacting mineral in a

1098 given lithology within a hill, a permeability structure will develop to allow more water to 
1099 flow through the weathered rock as groundwater than through the upper layer as

1100 interflow. In this way, the more soluble and abundant mineral can be dissolved and

1101 removed at the same rate as the less soluble and less abundant mineral. Of course, such

1102 flow patterns cannot occur if the rock remains impermeable and unfractured, i.e., if it

1103 evolves like the VA diabase. For this reason, we have emphasized permeability-

1104 enhancing reactions. In fact, the compositional range that is likely to experience more

1105 groundwater than interflow overlaps with the composition that is likely to experience

1106 oxidation-induced fracturing because this composition often contains biotite. The content

1107 of biotite may be a good predictor of weathering-induced fracturing and deep

1108 groundwater flow through weathered rock because biotite has been commonly observed

1109 to swell during oxidation and has been inferred to create fractures. This is consistent, for

1110 example, with the observation that regolith is thicker on biotite-bearing pelitic schists

1111 than sericite-chlorite phyllites in the Piedmont (Pavich et al., 1989) or that little

1112 weathering occurs on biotite-lacking leucogranites but deep weathering occurs on biotite

1113 granites (Dewandel et al., 2006).

1114

1115 Of course, the ratio of $\mathrm{O}_{2}$ to $\mathrm{CO}_{2}$ in the soil atmosphere varies from location to location,

1116 and high $\mathrm{O}_{2}$ in the soil atmosphere in some areas might allow oxidation-induced

1117 fracturing to drive deep infiltration even in rock with high $\mathrm{FeO}$ content. For example, in

1118 contrast to Fig. 2A, some diabase units in Virginia and Pennsylvania (PA) show

1119 spheroidal weathering (Pavich et al., 1989; Hausrath et al., 2011) and some have

1120 attributed this type of weathering to oxidation-induced fracturing (Fletcher et al., 2006).

1121 A difference between the VA diabase and the spheroidally weathered PA diabase is that 
1122 the former is a slower-eroding, coarser-grained sill while the latter is a faster-eroding

1123 finer-grained dike. In the PA dike, for example, the grain size of the feldspar and

1124 pyroxene varies between hundreds of microns and $1 \mathrm{~mm}$, whereas in the VA diabase the

1125 grain size is 1-2 mm. In the Piedmont, finer-grained diabase units exhibit better-

1126 developed jointing than the coarser-grained units (Roberts, 1928). Such jointing likely

1127 allows oxygenated water to access deeper parts of the diabase profile. Under such well-

1128 drained conditions, oxygen may be maintained at concentrations that crack the rock even

1129 though it is $\mathrm{FeO}-$ rich $\left(R^{o}=0.04\right)$. The importance of fracture spacing in determining the

1130 depth of weathering on diabase in the VA Piedmont was emphasized previously by

1131 Pavich et al. (1989).

1132

1133 In summary, in massive mafic rocks weathering in a hill at steady state, $Q_{i n} / Q_{g w}$ is large

1134 because the rock does not fracture during weathering and reaction fronts do not separate

1135 (Fig. 9). In felsic rocks that contain biotite, $Q_{i n} / Q_{g w}$ becomes small because the protolith

1136 permeability increases because of weathering-induced fracturing driven by biotite

1137 oxidation deep in the weathered rock. The ratio $Q_{i n} / Q_{g w}$ may also become small in pyrite-

1138 rich rocks that oxidize and develop deep high-flow zones. Given the importance of

1139 oxygen in driving fracturing, the actual delivery of oxygen to deep weathering - by

1140 preexisting vertical fractures in the system — also affects the extent of oxidation-induced 1141 fracturing.

1142

\section{9. Reaction front depth intervals as valves}


1144 If hills weather and erode at steady state, then these calculations show that the

1145 permeability of the interfaces between the soil, saprolite, and weathered rock must evolve

1146 until $\frac{Q_{g w}}{Q_{p}}=\frac{\Delta \rho_{2}^{(2)}}{\Delta \rho_{1}^{(1)}} \frac{C_{1}^{e}}{C^{e}}$ (Eq. 12). In other words, hills that contain minerals of different

1147 solubility and reactivity evolve to develop permeability in the upper flow zone, $K_{\text {int }}$, and

1148 lower flow zone, $K_{g w}$, that allows the partitioning of $Q_{p}$ into $Q_{\text {int }}$ and $Q_{g w}$ so that $U=E=$

$1149 W$. This idea is an extension to the idea promoted earlier by Pavich (1986): soil acts 'to

1150 partition rainfall into evapotranspiration, runoff, and recharge to the saprolite'. We argue

1151 that the hill itself develops a permeability architecture consisting of massive soil and soil,

1152 characterized by slow-dissolving mineral reactions (often the alkali-containing minerals),

1153 and saprolite and weathered rock, characterized by fast-dissolving mineral reactions

1154 (often, $\mathrm{Na}$ - and Ca-containing minerals) and that this architecture partitions $Q_{p}$ into $Q_{\text {int }}$

1155 and $Q_{g w}$ (see Fig. 7):

1156

$$
\frac{Q_{\text {int }}}{Q_{g w}}=\frac{H_{\text {int }}}{H_{g w}} \frac{K_{\text {int }}}{K_{g w}} \frac{\Delta B_{1}}{\Delta B_{2}}
$$

1158

1159 Certain depth intervals act as valves that partition the water flows, and the reaction fronts

1160 at these depths can cause the valve behavior and record the water flows at the valves.

1162 As pointed out previously, the ratio $\frac{\Delta \rho_{1}^{(1)}}{\Delta \rho_{2}^{(2)}}$ largely determines whether $Q_{i n t}$ and $Q_{g w}$ are

1163 both important at steady state. In the granite, the ratio (i.e., the ratio of potassium to

1164 plagioclase feldspar) is $<1$, and most water leaves the hill as groundwater. In contrast, in 
1165 the Rose Hill shale, the ratio > 1, and most water leaves as interflow. The zones of high-

1166 volume flow in these two quartzo-feldspathic rocks are separated over tens of meters

1167 depth. Like the shale, the value of $\frac{\Delta \rho_{1}^{(1)}}{\Delta \rho_{2}^{(2)}}$ for the diabase, i.e., the ratio of plagioclase

1168 feldspar to pyroxene, is $>1$, and most water leaves as interflow. However, in the massive

1169 diabase, the feldspar and pyroxene reaction fronts are closely co-located, and interflow

1170 and groundwater flow are co-located within a narrow depth interval. In the more felsic

1171 shale and granite, $\mathrm{RF}_{1}$ and $\mathrm{RF}_{2}$ separate by meters.

1172

1173 The separation of reaction fronts is determined partly by chemistry (soil gas, mineral

1174 composition, mineral abundance) and partly by the density of fractures. Felsic or highly

1175 fractured rocks separate into upper and lower dissolution zones that host interflow and

1176 groundwater flow respectively. The upper zone is dominated by dissolution by $\mathrm{CO}_{2}$ and

1177 organic acids while the lower zone is dominated by reactions with $\mathrm{O}_{2}$, the remaining $\mathrm{CO}_{2}$,

1178 and any $\mathrm{H}_{2} \mathrm{SO}_{4}$ generated by pyrite. In contrast, massive mafic rocks with low $R^{o}$ are not

1179 as likely to develop separated fronts because they are less likely to experience oxidation-

1180 induced fracturing. Unless they are characterized by preexisting fractures due to cooling

1181 or tectonics, these lithologies develop only one zone of important lateral flow because the

1182 reaction fronts remain narrow and unseparated with little of the water flow penetrating

1183 weathering rock. Even when these rocks are fractured, regolith depth, and separation of

1184 fronts remains smaller than on quartzo-feldspathic rocks (Pavich et al., 1989).

1185

1186 When the permeability of the interflow zone is much larger than that of the groundwater

1187 flow zone and $\Delta B_{1} \geq \Delta B_{2}$, as observed for rocks like the Rose Hill shale, much of the 
1188 solubilized mass of the rock leaves the system in interflow. In contrast, when $\frac{\Delta \rho_{1}^{(1)}}{\Delta \rho_{2}^{(2)}}<1$,

1189 much of the solubilized mass leaves at depth because of the high secondary permeability

1190 in the weathered rock. For example, in massive granites in the Piedmont that have very

1191 little primary permeability, drillers report highly permeable sand and boulders at the

1192 saprolite-weathered rock interface (Nutter, 1969). We argue that this high permeability

1193 results from weathering-induced fracturing and oxidative dissolution of pyrite and we

1194 point to previous studies as evidence for such phenomena (Jones, 1985; Taylor and

1195 Eggleton, 2001; Dewandel et al., 2006; Legout et al., 2007; Ayraud et al., 2008;

1196 Lachassagne et al., 2011; Brantley et al., 2013b; Navarre-Sitchler et al., 2015).

1198 Finally, it is important to note that the notion of steady state for weathering and erosion is

1199 perhaps a 'convenient fiction' (Phillips, 2010). Steady state is nonetheless often assumed

1200 and is probably useful in temperate regions such as the Piedmont rocks discussed

1201 throughout this paper (Pavich et al., 1989). Our model may therefore be useful to

1202 understand such systems. On the other hand, the implications of our model - that

1203 mineral solubility must be taken into account in considerations of weathering advance

1204 and erosion rates if steady state is ever to be attained - may also be useful in disproving 1205 steady state in some systems.

1206

1207 10. Conclusions

1208

1209 Many observations of water flow within hills have documented that water can flow

1210 laterally in the mostly unsaturated zone as well as at depth (Tromp-van Meerveld et al., 
1211 2007; Ayraud et al., 2008; Katsura et al., 2008; van Meerveld et al., 2015). Conceptual

1212 and numerical models of such flow are needed.

1213

1214 We describe a conceptual model for hills on relatively impermeable bedrock in regions

1215 where precipitation is greater than potential evapotranspiration. In our model, water flows

1216 in two main zones of water table fluctuation: an upper interflow zone that forms when the

1217 water table is high or perched, and a lower groundwater zone. This latter zone may

1218 represent the zone of fluctuation of the regional water table but it can also be a layer well

1219 below the regional water table that is a zone of intense fracturing and friable weathered

1220 rock. Such deep fractured and friable layers have been identified repeatedly in

1221 groundwater studies of crystalline rock (e.g. Jones, 1985; Dewandel et al., 2006; Legout

1222 et al., 2007; Lachassagne et al., 2011). Importantly, the two zones of water table

1223 fluctuation are also depth intervals that record significant biogeochemical reaction, i.e.,

1224 reaction fronts. Indeed, these reaction fronts may be a main cause of the porosity and

1225 permeability that maintain flow in the two zones. For example, clay precipitation or

1226 deposition may cause or contribute to the formation and maintenance of impermeable

1227 layers that underlie the upper flow zone. Likewise, the deep fractured and friable layer

1228 has been attributed to weathering-induced fracturing in crystalline rock at the base of the

1229 weathering profile (Lachassagne et al., 2011). Our model is very different from a recent

1230 model that emphasized only the properties of the protolith (Rempe and Dietrich, 2014)

1231 because our concept emphasizes the dual importance of the protolith and the regolith in

1232 controlling the fluxes of fluids and the depth of weathering.

1233 
1234 The zone of interflow is typically co-located with a shallow reaction front $\left(\mathrm{RF}_{1}\right)$ near the

1235 bottom of soil or massive soil. The $\mathrm{RF}_{1}$ is dominated by $\mathrm{O}_{2}, \mathrm{CO}_{2}$, and organic acid

1236 reactions and is often associated with formation of a clay layer that can act as an aquitard.

1237 A second important reaction front, $\mathrm{RF}_{2}$, is co-aligned with or lies below the deeper

1238 regional groundwater table. The $\mathrm{RF}_{2}$ is typified by reactions with $\mathrm{O}_{2}$ (especially felsic

1239 rocks), $\mathrm{CO}_{2}$ (especially mafic rocks), or $\mathrm{H}_{2} \mathrm{SO}_{4}$ (pyrite-containing rocks). In massive

1240 mafic rocks the two lateral flow zones do not tend to separate significantly, but in felsic

1241 rocks the zones can separate over tens of meters.

1242

1243 The reaction fronts document chemical loss or gain of minerals and are thus characterized

1244 by contrasts in permeability. As such, the reaction front depth intervals act like valves

1245 that reorient unsaturated water flow from predominantly vertical to lateral. The shunting

1246 of vertical to lateral flow at $\mathrm{RF}_{1}$ affects the rate of shallow and deep reactions because it

1247 removes reaction products from $\mathrm{RF}_{1}$ at the same time that it controls the extent of

1248 infiltration of water and reactants to $\mathrm{RF}_{2}$. Lateral flow at $\mathrm{RF}_{2}$ removes the most soluble

1249 minerals as groundwater flow.

1250

1251 At the same time that downward flowing water is reoriented from vertical to lateral at

1252 reaction fronts, rock material that advects upward through eroding hills is similarly

1253 redirected from vertical to lateral flow. Specifically, the most soluble minerals first leave

1254 the system at $\mathrm{RF}_{2}$ by dissolving into groundwater and flowing laterally to the channel. In

1255 felsic rocks this deep reaction zone typically marks the zone of consumption of $\mathrm{O}_{2}$.

1256 Oxidative dissolution is accelerated in the zone of water table fluctuation in response to 
1257 the entrainment of $\mathrm{O}_{2}$ into groundwater as the water table moves up and down. If

1258 minerals are not dissolved at $\mathrm{RF}_{2}$ or if the rate of upward advection of material is fast

1259 enough, unreacted minerals move up and through the dominantly unsaturated zone, and

1260 moderately soluble minerals reach $\mathrm{RF}_{1}$ where they dissolve. Only the least soluble

1261 minerals are exposed and removed at the land surface. Whether a given mineral becomes

1262 exposed at the land surface is a function of the residence time in the hill (determined by

1263 the erosion rate), the lithology (how much mineral is initially present), and the volume of

1264 water that flows past the mineral while in the subsurface (determined by the infiltration

1265 rate).

1266

1267 During the transit of water and particles through the hill, feedbacks between porefluid

1268 chemistry, particle size, fracture density, and soil gas drive the hill toward the condition

1269 where rates of uplift $=$ erosion $=$ weathering advance. Biota are often involved in these

1270 feedbacks. The slope of the hill is set by the erosion rate while the slopes of the reaction

1271 fronts are set by the rates of water influx. Importantly, the slope of the $\mathrm{RF}_{1}$ zone is

1272 controlled by precipitation $(P)$ minus evapotranspiration $(E T)$, but the slope of $\mathrm{RF}_{2}$ is

1273 controlled by $P-E T$ - interflow.

1274

1275 The two reaction zones tend to separate by meters under hills on felsic rocks but

1276 centimeters on mafic rocks because permeability opens up during weathering of felsic

1277 rock, allowing advection of water through reaction fronts. This infiltration increases the

1278 regolith thickness, reaction front thickness, and spacing of fronts. On massive mafic

1279 rocks, regolith and reaction fronts remain thinner, and chemical losses occur in co-located 
1280 shallow lateral flows. The most important exception to this felsic vs. mafic contrast is

1281 when high fracture or joint densities created by tectonics or cooling or other pre-existing

1282 conditions allow significant infiltration of oxygenated fluids into mafic rock. In such

1283 cases, the strong drainage can promote spheroidal weathering, thicker regolith, and the

1284 separation of reaction fronts.

1285

1286 According to these ideas, hills evolve toward a permeability architecture that allows

1287 material to be removed from the hill at steady state as solutes and as particles. The

1288 permeability is an emergent property of the hill that allows partitioning of water to

1289 remove minerals of different solubilities and rock material of different fracture toughness.

1290 Such lithological considerations should be useful in generating the conceptual

1291 underpinnings of quantitative hillslope hydrology models. Further collection of data

1292 about hill architecture would greatly aid in the development of numerical models that

1293 explore the feedbacks and evolution of fracture densities and chemical reactions and thus

1294 illuminate how hills work.

1295

1296 Acknowledgements

1297 S. Brantley acknowledges NSF Critical Zone Observatory grants EAR 12-39285 and 13-

129831726 for support for working on the Susquehanna Shale Hills Critical Zone Observatory

1299 in Penn State's Stone Valley Forest. The Forest is supported and managed by the Penn

1300 State Forestland Management Office in the College of Agricultural Sciences. SLB, ML,

1301 and GS acknowledge funding from DOE OBES DE-FG02-OSER15675. SLB 
1302 acknowledges discussions with F. Reis, S. Hynek, R. DiBiase, K. Bazilevskaya, C. Riebe, 1303 S. Holbrook, H. Kim, and D. Rempe and feedback from two anonymous reviewers. 1304 


\section{References}

Amundson, R., 2004. Soil Formation. In: Drever, J.I. (Ed.), Treatise in Geochemistry: Surface and Ground Water, Weathering, and Soils. Elsevier Pergamon, Amsterdam, pp. 1-35.

Anderson, S.P., Dietrich, W.E., Brimhall, G.H., 2002. Weathering profiles, mass balance analysis, and rates of solute loss: Linkages between weathering and erosion in a small, steep catchment. Geol. Soc. Am. Bull. 114 (9), 1143-1158.

Ayraud, V., Aquilina, L., Labasque, T., Pauwels, H., Molenat, J., Pierson-Wickmann, A.C., Durand, V., Bour, O., Tarits, C., Le Corre, P., Fourre, E., Merot, P., Davy, P., 2008. Compartmentalization of physical and chemical properties in hard-rock aquifers deduced from chemical and groundwater age analyses. Appl. Geochem. 23, 2686-2707 (Doi:2610.1016/j.apgeochem.2008.2606.2001).

Bacon, A.R., Richter, D., Bierman, P.R., Rood, D.H., 2012. Coupling meteoric ${ }^{10}$ Be with pedogenic losses of ${ }^{9} \mathrm{Be}$ to improve soil residence time estimates on an ancient North American interfluve. Geology 40, 847-850.

Balashov, V.N., Yardley, B.W.D., Lebedeva, M.I., 1999. Metamorphism in Marbles: Role Feedbacks Between Reaction, Fluid Flow, Pore Pressure and Creep. In: Jamtveit, B., Meakin P. (Eds.), Growth, Dissolution and Pattern Formation in Geosystems. Kluwer Academic Publishers, Dordrecht, pp. 367-380.

Banks, E.W., Simmons, C.T., Love, A.J., Cranswick, R., Werner, A.D., Bestland, E.A., Wood, M., Wilson, T., 2009. Fractured bedrock and saprolite hydrogeologic controls on groundwater/surface-water interaction: A conceptual model (Australia). Hydrogeol. J. 17 (8), 1969-1989.

Bazilevskaya, E., Lebedeva, M., Pavich, M., Rother, G., Parkinson, D.Y., Cole, D., Brantley, S.L., 2013. Where fast weathering creates thin regolith and slow weathering creates thick regolith. Earth Surf. Proc. Land. 38 (8), 847-858 (Doi:810.1002/esp.3369).

Bazilevskaya, E., Rother, G., Mildner, D.F.R., Pavich, M., Cole, D., Bhatt, M.P., Jin, L., Steefel, C.I., Brantley, S.L., 2014. How oxidation and dissolution in diabase and granite control porosity during weathering. Soil Sci. Soc. Am. J. (Doi:10.2136/sssaj2014.2104.0135).

Behrens, R., Bouchez, J., Schuessler, J.A., Dultz, S., Hewawasam, T., von Blanckenburg, F., 2015. Mineralogical transformations set slow weathering rates in loc-porosity metamorphic bedrock on mountain slopes in a tropical climate. Chem. Geol. 411, 283-298. http://dx.doi.org/10.1016/j.chemgeo.2015.07.008.

Berner, R.A., 1981. Kinetics of Weathering and Diagenesis. In: Lasaga, A.C., Berner, R.A., Fisher, G.W., Anderson, D.E., Kirkpatrick, R.J. (Eds.), Kinetics of Geochemical Processes. Mineralogical Society of America, Washington D.C., pp. 111-134. 
1346

1347

1348

1349

1350

1351

1352

1353

1354

1355

1356

1357

1358

1359

1360

1361

1362

1363

1364

1365

1366

1367

1368

1369

1370

1371

1372

1373

1374

1375

1376

1377

1378

1379

1380

1381

1382

1383

1384

1385

1386

1387

1388

1389

Bornstein, J., Hedstrom, W.E., Scott, F.R., 1980. Oxygen diffusion rate relationships under 3 soil conditions. Maine Agricultural Experiment Station: Orono Maine (U.S.A.), 1-12.

Brantley, S.L., Lebedeva, M., 2011. Learning to read the chemistry of regolith to understand the Critical Zone. Annu. Rev. Earth Pl. Sci. 39, 387-416.

Brantley, S.L., White, A.F., 2009. Approaches to Modeling Weathered Regolith. In: Oelkers, E., Schott, J. (Eds.), Thermodynamics and Kinetics of Water-Rock Interaction. Rev. Mineral. Geochem., pp. 435-484.

Brantley, S.L., Lebedeva, M., Hausrath, E.M., 2012. A Geobiological View of Weathering and Erosion. In: Knoll, A., Canfield, D., Konhauser, K. (Eds.), Fundamentals of Geobiology. Wiley-Blackwell, pp. 205-227 (Doi: 10.1002/9781118280874).

Brantley, S.L., Buss, H., Lebedeva, M., Fletcher, R.C., Ma, L., 2011. Investigating the complex interface where bedrock transforms to regolith. Appl. Geochem. S12S15 (Doi:10.1016/j.apgeochem.2011.1003.1017).

Brantley, S.L., Holleran, M.E., Jin, L., Bazilevskaya, E., 2013a. Probing deep weathering in the Shale Hills Critical Zone Observatory, Pennsylvania (U.S.A.): the hypothesis of nested chemical reaction fronts in the subsurface. Earth Surf. Proc. Land. (Doi:10.1002/esp.3415).

Brantley, S.L., Lebedeva, M., Bazilevskaya, E., 2013b. Relating weathering fronts for acid neutralization and oxidation to $\mathrm{pCO}_{2}$ and $\mathrm{pO}_{2}$. In: Farquhar, J., Kasting, J., Canfield, D. (Eds.), Treatise of Geochemistry, The Atmosphere -- History. Treatise on Geochemistry. Elsevier Amsterdam, The Netherlands.

Brimhall, G., Dietrich, W.E., 1987. Constitutive mass balance relations between chemical composition, volume, density, porosity, and strain in metasomatic hydrochemical systems: results on weathering and pedogenisis. Geochim. Cosmochim. Act. 51, 567-587.

Buol, S.W., Weed, S.B., 1991. Saprolite-soil transformations in the Piedmont and Mountains of North Carolina. Geoderma 51, 15-28.

Burke, B.C., Heimsath, A.M., Dixon, J.L., Chappell, J., Yoo, K., 2009. Weathering the escarpment: Chemical and physical rates and processes, south-eastern Australia. Earth Surf. Proc. Land. 1-18 (Doi: 10.1002/esp.1764).

Buss, H.L., Sak, P., Webb, R.M., Brantley, S., 2008. Weathering of the Rio Blanco quartz diorite, Luquillo Mountains, Puerto Rico: Coupling oxidation, dissolution and fracturing. Geochim. Cosmochim. Act. 72, 4488-4507.

Calmels, D., Gaillardet, J., France-Lanord, C., Brenot, A., 2007. Sustained sulfide oxidation by physical eorsion processes in the Mackenzie River basin: climatic perspectives. Geology 35, 1003-1006.

Carson, M.A., Kirkby, M.J., 1972. Hillslope Form and Process. Cambridge University Press, Cambridge.

Chigira, M., 1990. A mechanism of chemical weathering of mudstone in a mountainous area. Eng. Geol. 29, 119-138.

Chigira, M., Oyama, T., 1999. Mechanism and effect of chemical weathering of sedimentary rocks. Eng. Geol. 55, 3-14. 
Chigira, M., Sone, K., 1991. Chemical weathering mechanisms and their effects on engineering properties of soft sandstone and conglomerate cemented by zeolite in a mountainous area. Eng. Geol. 30, 195-219.

Cleaves, E.T., 1993. Climatic impact on isovolumetric weathering of a coarse-grained schist in the northern Piedmont Province of the central Atlantic states. Geomophology 8, 191-198.

Cleaves, E.T., Godfrey, A.E., Bricker, O.P., 1970. Geochemical balance of a small watershed and its geomorphic implications. Geol. Soc. Am. 81, 3015-3032.

Dewandel, B., Lachassagne, P., Wyns, R., Marechal, J.C., Krishnamurthy, N.S., 2006. A generalized 3-D geological and hydrogeological conceptual model of granite aquifers controlled by single or multiphase weathering. J. Hydrol. 330, 260-284 (Doi:210.1016/j.jhydrol.2006.1003.1026).

Drake, A.A., Jr., Froelich, A.J., 1977. Bedrock map of Fairfax County, Va., U.S. Geological Open-File Report 77-523, scale 1:48,000. United States Geological Survey.

Drake, H., Tullborg, E., MacKenzie, A.B., 2009. Detecting the near-surface redox front in crystalline bedrock using fracture mineral distribution, geochemistry and Useries disequilibrium. Appl. Geochem. 24, 1023-1039.

Duffy, C., Shi, Y., Davis, K., Slingerland, R., Li, L., Sullivan, P.L., Godderis, Y., Brantley, S.L., 2014. Designing a suite of models to explore critical zone function. Proc. Earth Planet. Sci. 7-15 (Doi: 10.1016/j.proeps.2014.1008.1003).

Eggler, D.H., Larson, E.E., Bradley, W.C., 1969. Granites, grusses, and the Sherman erosion surface, southern Laramie Range, Colorado-Wyoming. Am. J. Sci., 267 510-522.

Feakes, C.R., Holland, H.D., Zbinden, E.A., 1989. Ordovician Paleosols at Arisaig, Nova Scotia, and the Evolution of the Atmosphere. In: Bronger, A., Catt, J.A. (Eds.), Paleopedology: Nature and Application of Paleosols. Catena Supplement vol. 16, pp. 207-232.

Fetter, C.W., 2001. Applied Hydrogeology. Prentice Hall, Upper Saddle River, New Jersey (U.S.A.).

Fletcher, R.C., Brantley, S.L., 2010. Reduction of bedrock blocks as corestones in the weathering profile: observations and model. Am. J. Sci. 310, 131-164 (Doi:110.2475/2403.2010.2401).

Fletcher, R.C., Buss, H.L., Brantley, S.L., 2006. A spheroidal weathering model coupling porewater chemistry to soil thicknesses during steady-state denudation. Earth Planet. Sc. Lett. 244 (1-2), 444-457.

Follain, S., Minasny, B., McBratney, A.B., Walter, C., 2006. Simulation of soil thickness evolution in a complex agricultural landscape at fine spatial and temporal scales. Geoderma 133, 71-86.

Gleeson, T., Befus, K.M., Jasechko, S., Luijendijk, E., Bayani Cardenas, M., 2015. The global volume and distribution of modern groundwater. Nat. Geosci. (Doi:10,1038/NGEO2590).

Godderis, Y., Francois, L., Probst, A., Schott, J., Moncoulon, D., Labat, D., Viville, D., 2006. Modelling weathering processes at the catchment scale: The WITCH numerical model. Geochim. Cosmochim. Act. 70, 1128-1147. 
Graham, C.B., Woods, R.A., McDonnell, J.J., 2010. Hillslope threshold response to rainfall: (1) A field based forensic approach. J. Hydrol. 393 (1-2), 65-76.

Hack, J.T., 1960. Interpretation of erosional topography in humid temperate regions. Am. J. Sci. 258, 80-97.

Hausrath, E., Navarre-Sitchler, A.K., Sak, P.B., Williams, J.Z., Brantley, S.L., 2011. Soil profiles as indicators of mineral weathering rates and organic interactions on a Pennsylvania diabase. Chem. Geol. 290 (3-4), 89-100.

Hilley, G.E., Chamberlain, C.P., Moon, S., Porder, S., Willett, S.D., 2010. Competition between erosion and reaction kinetics in controlling silicate-weathering rates. Earth Planet. Sc. Lett. 293, 191-199 (Doi:110.1016/j.epsl.2010.1001.1008.

Holbrook, W.S., Riebe, C.S., Elwaseif, M., Hayes, J.L., Basler-Reeder, K., Harry, D.L., Malazian, A., Dosseto, A., Hartsough, P.C., Hopmans, J.W., 2014. Geophysical constraints on deep weathering and water storage potential in the Southern Sierra Critical Zone Observatory. Earth Surf. Proc. Land. 39, 366-380 (Doi:310.1002/esp.3502).

Holland, H.D., Zbinden, E.A., 1988. Paleosols and the evolution of the atmosphere: part I. In: Lerman, A., Meybeck, M. (Eds.), Physical and Chemical Weathering in Geochemical Cycles. Kluwer Academic Publishers, New York.

Hooper, R.P., Christophersen, N., Peters, N.E., 1990. Modelling stream-water chemistry as a mixture of soilwater end-members: An application to the Panola Mountain catchment, Georgia, USA. J. Hydrol. 116, 32-43.

Hopp, L., McDonnell, J.J., 2009. Connectivity at the hillslope scale: Identifying interactions between storm size, bedrock permeability, slope angle and soil depth. J. Hydrol. 376, 378-391.

Jamtveit, B., Hammer, O., 2012. Sculpting of Rocks by Reactive Fluids. Geochem. Persp. 1, 341-480.

Jin, L., Ravella, R., Ketchum, B., Bierman, P.R., Heaney, P., White, T.S., Brantley, S.L., 2010b. Mineral weathering and elemental transport during hillslope evolution at the Susquehanna/Shale Hills Critical Zone Observatory. Geochim. Cosmochim. Act. 74, 3669-3691.

Jin, L., Rother, G., Cole, D.R., Mildner, D.F.R., Duffy, C.J., Brantley, S.L., 2011. Characterization of deep weathering and nanoporosity development in shale $-\mathrm{a}$ neutron study. Am. Mineral. 96, 498-512 (Doi:410.2138/am.2011.3598).

Jin, L., Ravella, R., Ketchum, B., Bierman, P.R., Heaney, P., White, T., Brantley, S.L., 2010a. Mineral weathering and elemental transport during hillslope evolution at the Susquehanna/Shale Hills Critical Zone Observatory. Geochim. Cosmochim. Act. 74 (13), 3669-3691.

Jobbagy, E.G., Jackson, R.B., 2001. The distribution of soil nutrients and depth: Global patterns and the imprint of plants. Biogeochemistry 53, 51-77.

Jones, M.J., 1985. The weathered zone aquifers of the basement complex areas of Africa. Q. J. Eng. Geol. London 18, 35-46.

Katsura, S., Kosugi, K., Mizutani, T., Okunaka, S., Mizuyama, T., 2008. Effects of bedrock groundwater on spatial and temporal variations in soil mantle groundwater in a steep granitic headwater catchment. Water Resour. Res. 44 (Doi:10.1029/2007WR00610). 
Lachassagne, P., Wyns, R., Dewandel, B., 2011. The fracture permeability of Hard Rock Aquifers is due neither to tectonics, nor to unloading, but to weathering processes. Terra Nova 23 (3), 145-161.

Lebedeva, M., Brantley, S.L., 2013. Exploring geochemical controls on weathering and erosion of convex hillslopes: beyond the empirical regolith production function. Earth Surf. Proc. Land. 38 (15), 1793-1807. http://dx.doi.org/10.1002/esp.3424.

Lebedeva, M.I., Fletcher, R.C., Balashov, V.N., Brantley, S.L., 2007. A reactive diffusion model describing transformation of bedrock to saprolite. Chem. Geol. 244 (3-4), 624-645.

Lebedeva, M.I., Fletcher, R.C., Brantley, S.L., 2010. A mathematical model for steadystate regolith production at constant erosion rate. Earth Surf. Proc. Land. 35 (5), 508-524.

Legout, C., Molenat, J., Aquilina, L., Gascuel-Odoux, C., Faucheux, M., Fauvel, Y., Bariac, T., 2007. Solute transfer in the unsaturated zone-groundwater continuum of a headwater catchment. J. Hydrol. 332, 427-441 http://dx.doi.org/10.1016/j.jhydrol.2006.07.017.

Lichtner, P.C., 1988. The quasi-stationary state approximation to coupled mass transport and fluid-rock interaction in a porous medium. Geochim. Cosmochim. Act. 52, 143-165.

Lichtner, P.C., Waber, N., 1992. Redox front geochemistry and weathering: Theory with application to the Osamu Utsumi uranium mine, Pocos de Caldas, Brazil. J. Geochem. Explor. 45, 521-564.

Lonsdale, J.T., 1927. Geology of the gold-pyrite belt of the northeastern Piedmont, Virginia. Va. Geol. Surv. Bull. 30, 1-110.

MacQuarrie, K.T.B., Mayer, K.U., Jin, B., Spiessl, S.M., 2010. The importance of conceptual models in the reactive transport simulation of oxygen ingress in sparsely fractured crystalline rock. J. Contam. Hydrol. 112 (1-4), 64-76.

Maher, K., 2011. The role of fluid residence time and topographic scales in determining chemical fluxes from landscapes. Earth Plan. Sci. Lett. 312, 48-58 http://dx.doi.org/10.1016/j.epsl.2011.09.040.

McDonnell, J.J., 1990. A rationale for old water discharge through macropores in a steep, humid catchment. Water Resour. Res. 26 (11), 2821-2832.

McGlynn, B.L., McDonnell, J.J., 2003. Role of discrete landscape units in controlling catchment dissolved organic carbon dynamics. Water Resour. Res. 39 (4) (Doi:10.1029/2002WR001525).

McGuire, K.J., McDonnell, J.J., 2010. Hydrological connectivity of hillslopes and streams: Characteristic time scales and nonlinearities. Water Resour. Res. 46, W10543, (Doi:10510.11029/12010WR009341).

Minasny, B., McBratney, A.B., Salvador-Blanes, S., 2008. Quantitative models for pedogenesis - A review. Geoderma 144, 140-157.

Molnar, P., Anderson, R.S., Anderson, S.P., 2007. Tectonics, fracturing of rock, and erosion. J. Geophys. Res. 112 (F03014), 1-12

(Doi:10.11029/12005JF000433,002007). 
1524

1525

1526

1527

1528

1529

1530

1531

1532

1533

1534

1535

1536

1537

1538

1539

1540

1541

1542

1543

1544

1545

1546

1547

1548

1549

1550

1551

1552

1553

1554

1555

1556

1557

1558

1559

1560

1561

1562

1563

1564

1565

1566

1567

1568

1569

Moore, J., Lichtner, P.C., White, A.F., Brantley, S.L., 2012. Using a reactive transport model to elucidate differences between laboratory and field dissolution rates in regolith. Geochim. Cosmochim. Act. 93, 235-261.

Mudd, S.M., Furbish, D.J., 2004. Influence of chemical denudation on hillslope morphology. J. Geophys. Res. - Earth 109, F02001.

Nadan, B.J., Engelder, T., 2009. Microcracks in New England granitoids: A record of thermoelastic relaxation during exhumation of intracontinental crust. Geo. Soc. Am. Bull. 121 (1-2), 80-99 (Doi: 10.1130/B26202.26201).

Navarre-Sitchler, A., Brantley, S.L., 2007. Basalt weathering across scales. Earth Plan. Sci. Lett. 261 (1-2), 321-334.

Navarre-Sitchler, A., Cole, D.R., Rother, G., Jin, L., Buss, H.L., Brantley, S.L., 2013. Porosity and surface area evolution during weathering of two igneous rocks. Geochim. Cosmochim. Act. 109, 400-413, doi.org/410.1016/j.gca.2013.1002.1012.

Navarre-Sitchler, A., Brantley, S.L., Rother, G., 2015. How porosity increases during incipient weathering of crystalline silicate rocks. In: Steefel, C., Emmanuel, S., Anovitz, L. (Eds.), Pore-scale Geochemical Processes. MIneral. Soc. Am. - Geo. Soc., pp. 331-354.

Nesbitt, H.W., Markovics, G., 1997. Weathering of a granodioritic crust, long-term storage of elements in weathering profiles, and petrogenesis of siliciclastic sediments. Geochim. Cosmochim. Act. 61 (8), 1653-1670.

Nordstrom, D.K., 2000. Advances in the hydrogeochemistry and microbiology of acid mine waters. Int. Geol. Rev. 42 (6), 499-515.

Nutter, L., 1969. Ground-water occurrence in the Maryland Piedmont. Maryland Geological Survey Report of Investigations, 10, 1-54.

Ollier, C.D., 1967. Spheroidal weathering, exfoliation and constant volume alteration. Zeitschrift fuer Geomorphologie 11 (1), 103-108.

Pain, C.F., Ollier, C.D., 1996. Regolith stratigraphy: principles and problems. J. Aust. Geol. 16 (3), 197-202.

Pavich, M.J., 1986. Processes and Rates of Saprolite Production and Erosion on a Foliated Granitic Rock of the Virginia Piedmont. In: Colman, S.M., Dethier, D.P. (Eds.), Rates of Chemical Weathering of Rocks and Minerals. Academic Press, Orlando, FL, pp. 551-590.

Pavich, M.J., Brown, L., Valette-Silver, J.N., Klein, J., Middleton, R., $1985 .{ }^{10} \mathrm{Be}$ analysis of a quaternary weathering profile in the Virginia Piedmont. Geology 13 (1), 3941.

Pavich, M., Leo, G.W., Obermeier, S.F., Estabrook, J.R., 1989. Investigations of the characteristics, origin, and residence time of the upland residual mantle of the Piedmont of Fairfax County, Virginia. U.S. Geological Survey Professional Paper 1352, U.S. Geological Survey, 1-58.

Pelletier, J.D., 2008. Quantitative Modeling of Earth Surface Processes. Cambridge Univ. Press.

Peters, N.E., Freer, J., Aulenbach, B.T., 2003. Hydrologic dynamics of the Panola Mountain Research Watershed, Georgia. Ground Water 41, 973-988.

Phillips, J.D., 2010. The convenient fiction of steady-state soil thickness. Geoderma 156, 389-398, (Doi:310.1016/j.geoderma.2010.1003.1008). 
Portenga, E.W., Bierman, P.R., 2011. Understanding Earth's eroding surface with ${ }^{10}$ Be. GSA Today 21, 4-10.

Price, J.R., Heitmann, N., Hull, J., Szymanski, D., 2008. Long-term average mineral weathering rates from watershed geochemical mass balance methods: using mineral modal abundances to solve more equations in more unknows. Chem. Geol. 254, 36-51.

Rasmussen, C., Troch, P.A., Chorover, J., Brooks, P., Pelletier, J., Huxman, T.E., 2011. An open system framework for integrating critical zone structure and function. Biogeochemistry 102, 15-29.

Rempe, D.M., Dietrich, W.E., 2014. A bottom-up control on fresh-bedrock topography under landscapes. P. Natl. Acad. Sci. USA 111 (18), 6576-6581.

Rice, T.J., Jr., Buol, S.W., Weed, S.B., 1985. Soil saprolite profiles, derived from mafic rocks in the North Carolina Piedmont. I. Chemical, morphological, and mineralogical characteristics and transformations. Soil Sci. Soc. Am. J. 49, 171178.

Riebe, C.S., Kirchner, J.W., Granger, D.E., Finkel, R.C., 2001. Strong tectonic and weak climatic control of long-term chemical weathering rates. Geology 29 (6), 511-514.

Roberts, J.K., 1928. The geology of the Triassic. State of Virginia, Conservation and Development Commission, Va Geol. Surv. Bull. 29, 1-177.

Salve, R., Rempe, D.M., Dietrich, W.E., 2012. Rain, rock moisture dynamics, and the rapid response of perched groundwater in weathered, fractured argillite underlying a steep hillslope. Water Resour. Res. 48, 25.

Shuman, B.N., Marsicek, J., 2016. The structure of Holocene climate change in midlatitude North America. Quaternary Sci. Rev. 141, 38-51. http://dx.doi.org/10.1016/j.quascirev.2016.03.009.

Smith, R.C., Rose, A.W., Lanning, R.M., 1975. Geology and geochemistry of Triassic diabase in Pennsylvania. Geol. Soc. Am. Bull. 86, 943-955.

St. Clair, J., Moon, S., Holbrook, S., Perron, J.T., Riebe, C.S., Martel, S., Carr, B., Harman, C., Singha, K., Richter, D., 2015. Geophysical imaging reveals topographic stress control of bedrock weathering. Science 350 (6260), 534-538 (Doi: 510.1126/science.aab2210).

Stallard, R., 1995. Relating Chemical and Physical Erosion. In: White, A.F., Brantley, S.L. (Eds.), Chemical Weathering Rates of Silicate Minerals. Reviews in Mineralogy. Mineralogical Society of America, Washington, D.C., pp. 543-564.

Stallard, R.F., Edmond, J.M., 1983. Geochemistry of the Amazon 2. The influence of geology and weathering environment on the dissolved load. J. Geophys Res. 88, 9671-9688.

Steefel, C.I., 1993. 1DREACT: User Manual and Programmer's Guide, Richland, WA.

Sullivan, P.L., Hynek, S., Gu, X., Singha, K., White, T.S., West, N., Kim, H., Clarke, B., Kirby, E., Duffy, C., Brantley, S.L. Oxidative dissolution under the channel leads geomorphological evolution at the Shale Hills catchment. Am. J. Sci. (in press).

Tague, C., Grant, G.E., 2004. A geological framework for interpreting the low-flow regimes of Cascade streams, Willamette River Basin, Oregon. Water Resour. Res. 40 (W04303) (Doi:10.1029/2003WR002629).

Taylor, G., Eggleton, R.A., 2001. Regolith Geology and Geomorphology. John Wiley and Sons, Chichester. 
1616

1617

1618

1619

1620

1621

1622

1623

1624

1625

1626

1627

1628

1629

1630

1631

1632

1633

1634

1635

1636

1637

1638

1639

1640

1641

1642

1643

1644

1645

1646

1647

1648

1649

1650

1651

1652

1653

1654

1655

1656

1657

1658

1659

1660

1661

Torres, M.A., West, A.J., Li, G., 2014. Sulphide oxidation and carbonate dissolution as a source of $\mathrm{CO}_{2}$ over geological timescales. Nature 507, 346-349

(Doi:310.1038/nature13030).

Tóth, J., 1970. A conceptual model of the groundwater regime and the hydrogeologic environment. J. Hydrol. 10 (2), 164-176.

Tromp-van Meerveld, H.J., McDonnell, J.J., 2006. Threshold relations in subsurface stormflow 2: The fill and spill hypothesis: an explanation for observed threshold behavior in subsurface stormflow. Water Resour. Res.

(Doi:10.1029/2004WR003800).

Tromp-van Meerveld, H.J., Peters, N.E., McDonnell, J.J., 2007. Effectof bedrock permeability on subsurface stormflow and the water balance of a trenched hillslope at the Panola Mountain Research Watershed, Georgia, USA. Hydrol. Process. 21, 750-769 (Doi:710.1002/hyp.6265).

van Meerveld, H.J., Seibert, J., Peters, N.E., 2015. Hillslope-riparian-stream connectivity and flow directions at the Panola Mountain Research Watershed. Hydrol. Process. (Doi: 10.1002/hyp.10508).

Van Tassel, J.V., Grant, W.H., 1980. Granite disintegratino, Panola Mountain, Georgia. J. Geol. 88, 360-364.

Waldbauer, J., Chamberlain, P.C., 2005. Influence of Uplift, Weathering, and Base Cation Supply on Past and Future CO2 Levels. In: Baldwin, I.T., Caldwell, M.M., Heldmaier, G., Jackson, R., Lange, O.L., Mooney, H.A., Schulze, E.D., Sommer, U., Ehleringer, J., Denise Dearing, M., Cerling, T., (Eds.), A History of Atmospheric $\mathrm{CO} 2$ and Its Effects on Plants, Animals, and Ecosystems. Ecological Studies. Springer New York, pp. 166-184.

Welch, L.A., Allen, D.M., 2014. Hydraulic conductivity characteristics in mountains and implications for conceptualizing bedrock groundwater flow. Hydrogeol. J. 22, 1003-1026 (Doi: 1010.1007/s10040-10014-11121-10045).

West, N., Kirby, E., Bierman, P.R., Slingerland, R., Ma, L., Rood, D., Brantley, S.L., 2013. Regolith production and transport at the Susquehanna Shale Hills Critical Zone Observatory: Part 2 - Insights from meteoric 10Be. J. Geophys. Res. - Earth Surf. 118, 20.

West, N., Kirby, E., Bierman, P.R., Clarke, B.A., 2014. Aspect-dependent variations in regolith creep revealed by meteoric ${ }^{10} \mathrm{Be}$. Geology 42 (6), 4.

White, A.F., 2008. Quantitative Approaches to Characterizing Natural Chemical Weathering Rates. In: Brantley, S.L., Kubicki, J.D., White, A.F. (Eds.), Kinetics of Water-Rock Interaction. Springer, New York, pp. 469-544.

White, A.F., Blum, A.E., Schulz, M.S., Vivit, D.V., Stonestrom, D.A., Larsen, M., Murphy, S.F., Eberl, D., 1998. Chemical weathering in a tropical watershed, Luquillo Mountains, Puerto Rico: I. Long-term versus short-term weathering fluxes. Geochim. Cosmochim. Act. 62 (2), 209-226.

White, A.F., Bullen, T.D., Schultz, M.S., Blum, A.E., Huntington, T.G., Peters, N.E., 2001. Differential rates of feldspar weathering in granitic regoliths. Geochim. Cosmochim. Act. 65, 847-869.

White, A.F., Blum, A.E., Schulz, M.S., Huntingdon, T.G., Peters, N.E., Stonestrom, D.A., 2002. Chemical Weathering of the Panola Granite: Solute and Regolith Elemental Fluxes and the Dissolution Rate of Biotite. In: Hellmann, R., Wood, 

S.A. (Eds.), Water-rock Interaction, Ore Deposits, and Environmental 2016. Investigation of a diabase-derived regolith profile from Pennsylvania: Mineralogy, chemistry and Fe isotope fractionation. Geoderma 273, 83-97. http://dx.doi.org/10.1016/j.geoderma.2016.03.004. 
Figure captions.

Fig. 1. Schematic hillslope showing $L$ (distance from the divide to the channel head along the $x$ axis), $\Delta B_{2}$ (relative elevation of unweathered rock above the elevation of the channel head), $\Delta B_{1}$ (relative elevation of the base of interflow above the elevation of the channel head), and $r$ (elevation of ridgetop above the channel head). The groundwater flux $Q_{g w}\left(\mathrm{~L}^{3} \mathrm{~T}^{-1}\right)$ is localized at the solid line, and the interflow water flux $Q_{\text {int }}\left(\mathrm{L}^{3} \mathrm{~T}^{-1}\right)$ is localized at the dashed line. Although not shown, $H$ is the total thickness of regolith and is equivalent to $r-\Delta B_{2}$ under the hilltop (located at $x=0$ ). In other words, regolith is here defined to include all weathered or altered material.

Fig. 2. Schematics showing reaction fronts within regolith at ridgetops for three systems. The upper surface is the land surface (see text). Here $\tau$ is the fractional depletion of each mineral or component compared to immobile element in the protolith. A depletion of $0 \%$ is plotted as 0 and $100 \%$ depletion is plotted as -1. (A) Diabase in the Virginia Piedmont, where reaction fronts largely do not separate. The profile-initiating mineral is high-Fe(II) pyroxene, the major-porosity initiating mineral is augite, and the soil-initiating mineral is plagioclase. (B) Granite in the Virginia Piedmont, where reaction fronts separate over tens of meters. The profile-initiating reaction is biotite oxidation, the major porosity-initiating reaction is plagioclase dissolution, and the soil-initiating reaction is dissolution of alkali-containing minerals (orthoclase feldspar, mica). (C) Rose Hill shale from central Pennsylvania, where reaction fronts separate over tens of meters. The profile-initiating mineral reaction is shown as pyrite oxidation, the major porosityinitiating reaction as carbonate dissolution, and the soil-initiating reaction as illite dissolution. (It has not been possible to distinguish whether the deepest reaction involves pyrite or carbonate, but pyrite oxidation is shown here to be deepest, for simplicity. Likewise the carbonate mineral varies from ankerite to calcite but is shown here as calcite for simplicity.) Data from Bazilevskaya et al. (2013, 2014); Jin et al. (2010, 2011), Pavich et al. (1989), and Stinchcomb (unpub.).

Fig. 3. (A)-(H) Simulated steady-state hillslopes calculated for the model in Eqs. (1)-(5) for different values of erosion rate $E$ and vertical Darcy velocity $q_{y}$ for rock of composition $40 \%$ albite and $50 \%$ quartz. The model simulate albite weathering to kaolinite (quartz is inert). Colors show contours for the extent of reaction (i.e., the extent of weathering at each depth). Unweathered bedrock is represented by blue: warmer colors represent greater extent of reaction and thus greater fraction of kaolinite (see key to right of each diagram). When $100 \%$ of the albite is reacted to kaolinite ( + pore space), extent of reaction $=1$. For the simulations, $L=20 \mathrm{~m}$. Other parameters in Eq. (5) were held constant. See further information in caption of Fig. 5.

Fig. 4. Summary of calculations shown in Fig. 3: (A) contours of chemical depletion fraction, $\mathrm{CDF}$, calculated for the simulated hills in Fig. 3 on a graph of vertical Darcy velocity $q_{y}$ versus erosion rate $E$; (B) contours of $E$ on a graph of $C D F$ versus $q_{y}$. Additional calculations described in text (see also Fig. 5) are shown in (C): calculated model CDF values are plotted versus quartz volume fraction in the protolith. In this context, CDF is the fraction of the hill that was removed by solubilization reactions (the fraction of total denudation that was removed by chemical weathering (see supplementary information)). For panel (C), $E=2 \cdot 10^{-5} \mathrm{~m} \mathrm{y}^{-1}, q_{y}=0.4 \mathrm{~m} \mathrm{y}^{-1}$. 
Fig. 5. The L\&B model-simulated steady-state hillslopes showing the weathering extent (colored contours) as a function of quartz volume fraction in protolith, as noted. For description of contours, see Fig. 3 caption. The steady state thickness of regolith under the ridge and along the hillslope both increase as the \% quartz increases. Here, the erosion rate and the vertical Darcy velocity were held constant at $E=2 \cdot 10^{-5} \mathrm{~m} \mathrm{y}^{-1}, q_{y}=0.4 \mathrm{~m} \mathrm{y}^{-1}$. For all cases here and Figs. 3 and 4, the intrinsic kinetic constant was set as $k_{a b}=3.87 \cdot 10^{-10} \mathrm{~mol} \mathrm{~m}^{-2} \mathrm{~s}^{-1}$. The effective constant was calculated from the equation, $k=2 k_{a b} s_{a b} \phi_{a b}^{0} \Psi \quad$ (Lebedeva et al., 2010). Note that $k$ depends on $\phi_{a b}^{0}:$ (A) $k=1.95 \cdot 10^{-8} \mathrm{~s}^{-1}$; (B) $k=1.3 \cdot 10^{-8} \mathrm{~s}^{-1}$ (also for Figs. 3 and 5); and (C) $k=0.65 \cdot 10^{-8}$ $\mathrm{s}^{-1}$. In later L\&B papers (Lebedeva and Brantley, 2013; Lebedeva et al., 2015) the factor $\phi_{a b}^{0}$ is included in $\Psi$ and the effective constant is written as $k=2 k_{a b} s_{a b} \Psi$. Parameters are: (A) $\phi_{a b}^{0}=0.6, \phi_{q t z}=0.3, \phi=0.1, \mathrm{CDF}=0.999,(\mathrm{~B}) \phi_{a b}^{0}=0.4, \phi_{q t z}=0.5, \phi=0.1, \mathrm{CDF}=0.998 ;(\mathrm{C})$ $\phi_{a b}^{0}=0.2, \phi_{q t z}=0.7, \phi=0.1, \mathrm{CDF}=0.982$. The specific surface area $s_{a b}=3.5 \times 10^{4} \mathrm{~m}^{2} \mathrm{~m}^{-3}$ and the correction factor $\Psi=1.2 \times 10^{-3} \mathrm{~m}^{3} \mathrm{~mol}^{-1}$.

Fig. 6. Summary compilation of thickness of ridgetop regolith for case studies discussed in this paper and for other lithologies in the VA Piedmont (Pavich et al., 1989). The systems are all assumed to be experiencing the same rates of uplift and, given the long exposure times, similar rates of erosion. The one exception is the symbol for Shale Hills, where the plotted value derives from an estimate for ridges in the Susquehanna Shale Hills Critical Zone Observatory. The erosion rate of that system is higher than the rate estimated for the Piedmont (see text). This figure shows that regolith is thicker on rocks with a lower fraction of soluble mineral (i.e., higher quartz content).

Fig. 7. A conceptual model for a hill with two layers of lateral water flow (see also Fig. 1 where some variables are defined). The upper layer is soil and the bottom layer is unweathered rock (UWR). $\mathrm{RF}_{1}$ and $\mathrm{RF}_{2}$ are the bottom of the upper and lower reaction fronts, respectively, as described in the text. These fronts are co-localized with zones of water table fluctuation for interflow and groundwater flow, respectively. $H_{i n t}$ and $H_{g w}$ are the depth intervals of water table fluctuation or, alternately, thicknesses of the high-permeability flow layers; these layers are characterized by hydraulic conductivities $K_{\text {int }}$ and $K_{g w}$, for the interflow and groundwater flow zones, respectively. The semitransparent vertical arrows indicate the vertical flow of water in the unsaturated zone between land surface and interflow and between interflow and groundwater flow zones.

Fig. 8. The weathering domain of the two-layer lateral-flow hill model depicted in 1D. In reality, all horizontal lines are slightly inclined so that this is a parallelogram with sides parallel to a hillslope. The angle of the hillslope is assumed to be small so that the rectangle is a reasonable approximation of this domain. The soil surface moves down at a constant erosion rate and is 
considered equal to the weathering advance rate $W \cdot Q^{(0)}$ and $Q^{(1)}$ represent water flow in the unsaturated zone between land surface and the upper interflow zone, or between the interflow and groundwater flow zones, respectively. Lateral flow could occur anywhere a permeability contrast is large enough to allow transient saturation; however, lateral flow is largely localized at the upper or lower reaction fronts, i.e., $\mathrm{RF}_{1}$ or $\mathrm{RF}_{2}$, respectively. The dissolved concentrations of the reacting mineral at equilibrium in the interflow and groundwater flow volumes are $C_{1}^{e q}$ and $C_{2}^{e q}$, respectively. The upper hachured layer is the zone of water table fluctuation for the water table at highstand or for a perched layer; the lower hachured layer is the zone of water table fluctuation of the present-day regional groundwater table or a relict fluctuation zone from a previously-deeper water table (see text). For mafic systems such as the diabase in Fig. 2, RF 1 and $\mathrm{RF}_{2}$ are almost coincident and flow does not separate into two zones. For felsic systems or fractured systems such as the granite and shale in Fig. $2, \mathrm{RF}_{1}$ and $\mathrm{RF}_{2}$ separate by meters or tens of meters: in this case the lower zone of flow is typically an oxidation zone and is marked by the intense biogeochemical reactivity of minerals such as biotite and pyrite. Some variables are defined in Fig. 1 or 7. 


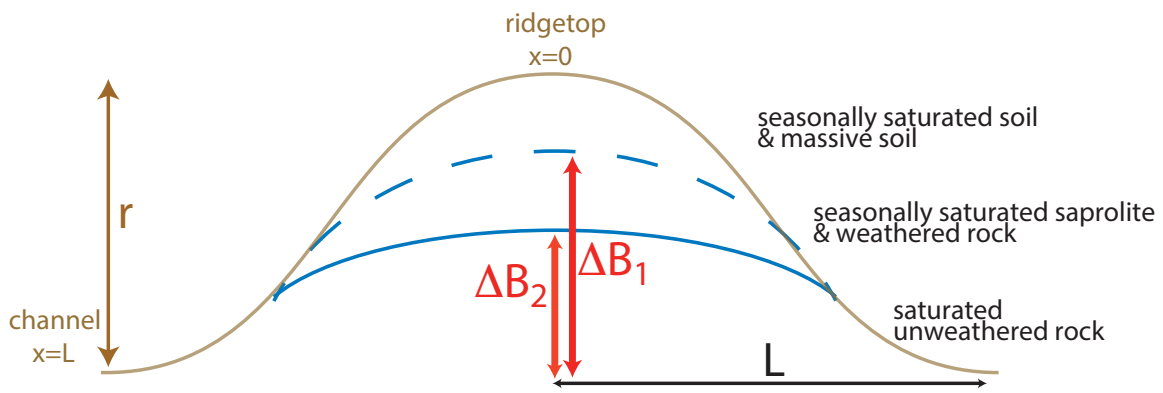


(A)

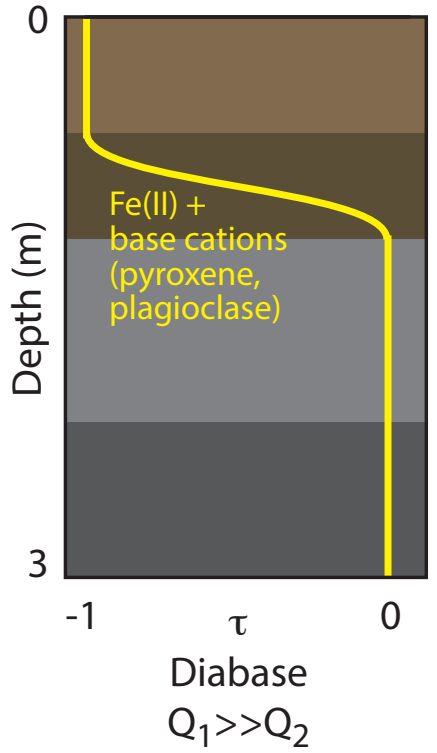

(B)

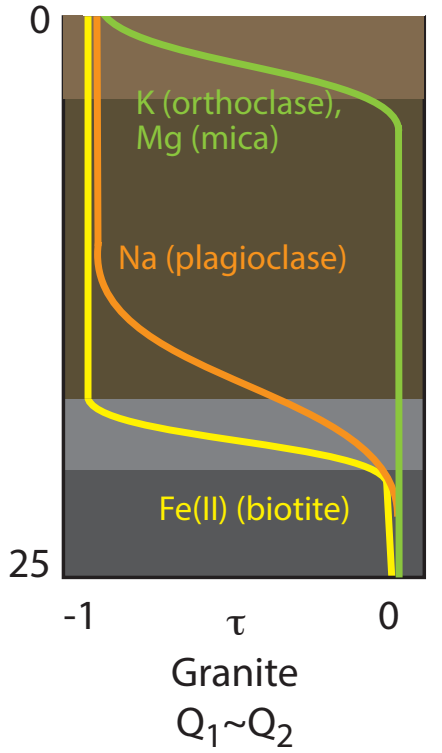

(C)

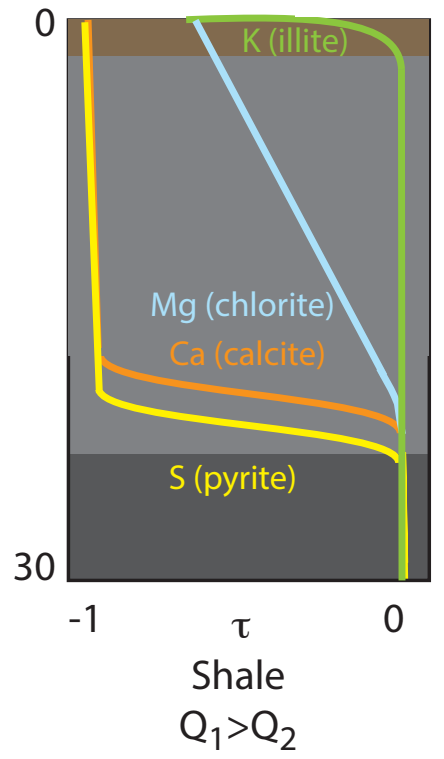

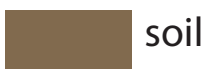

saprolite WR UWR 

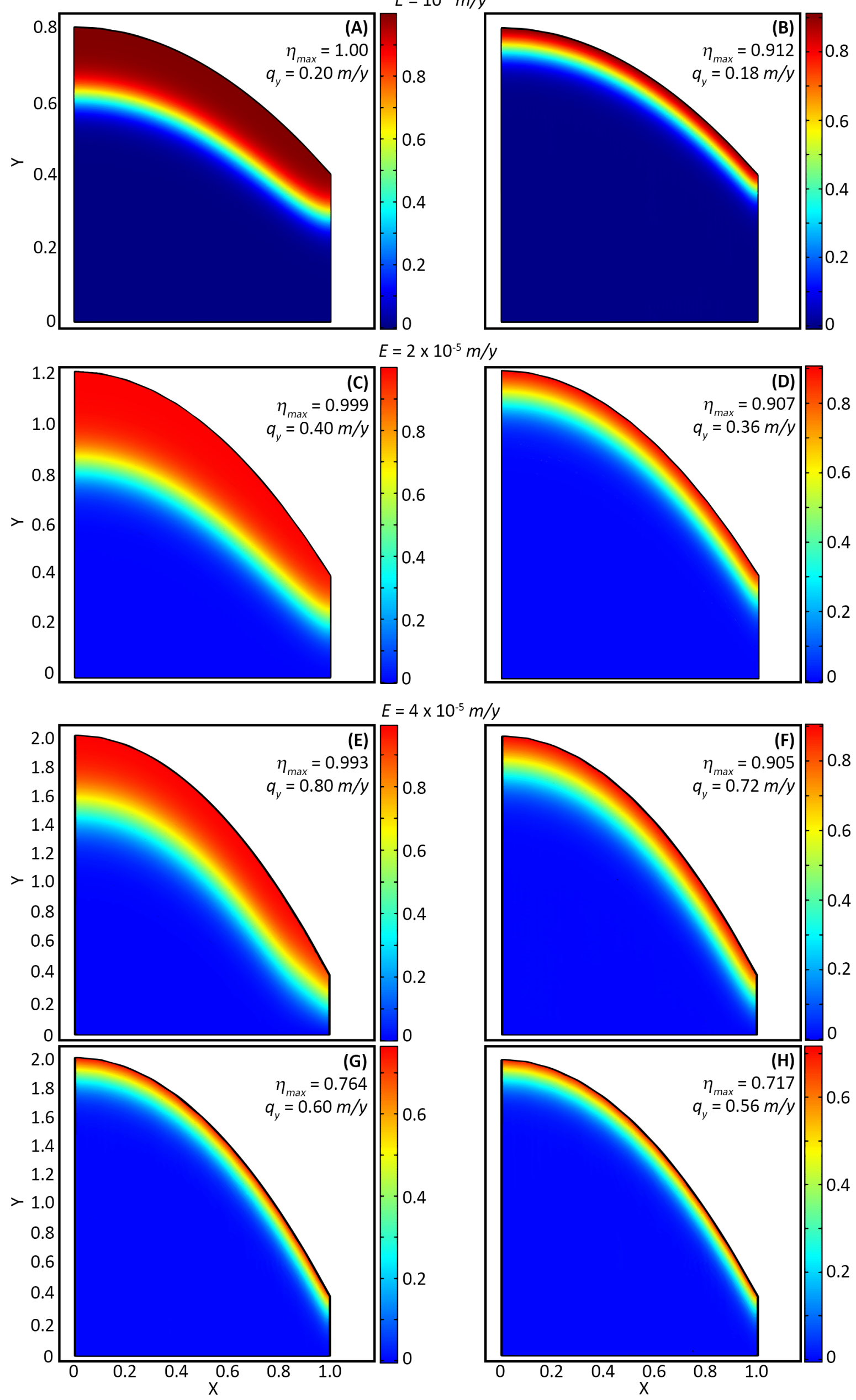


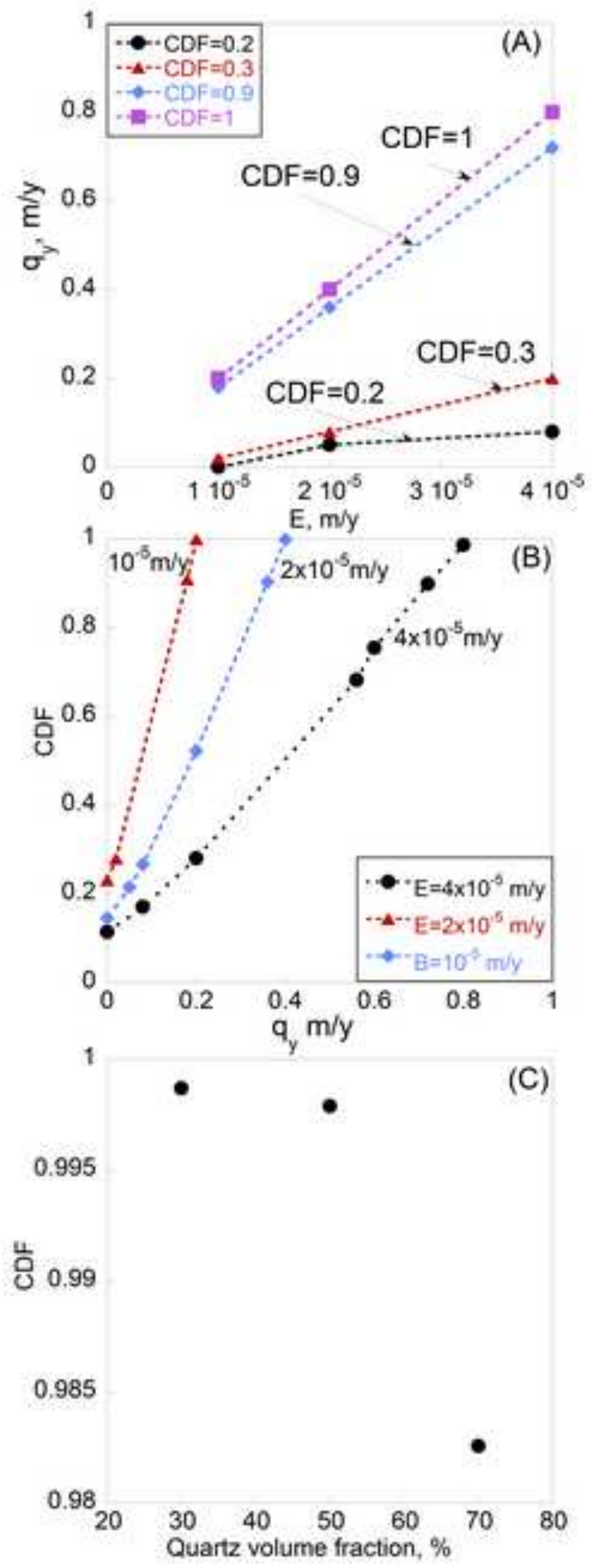




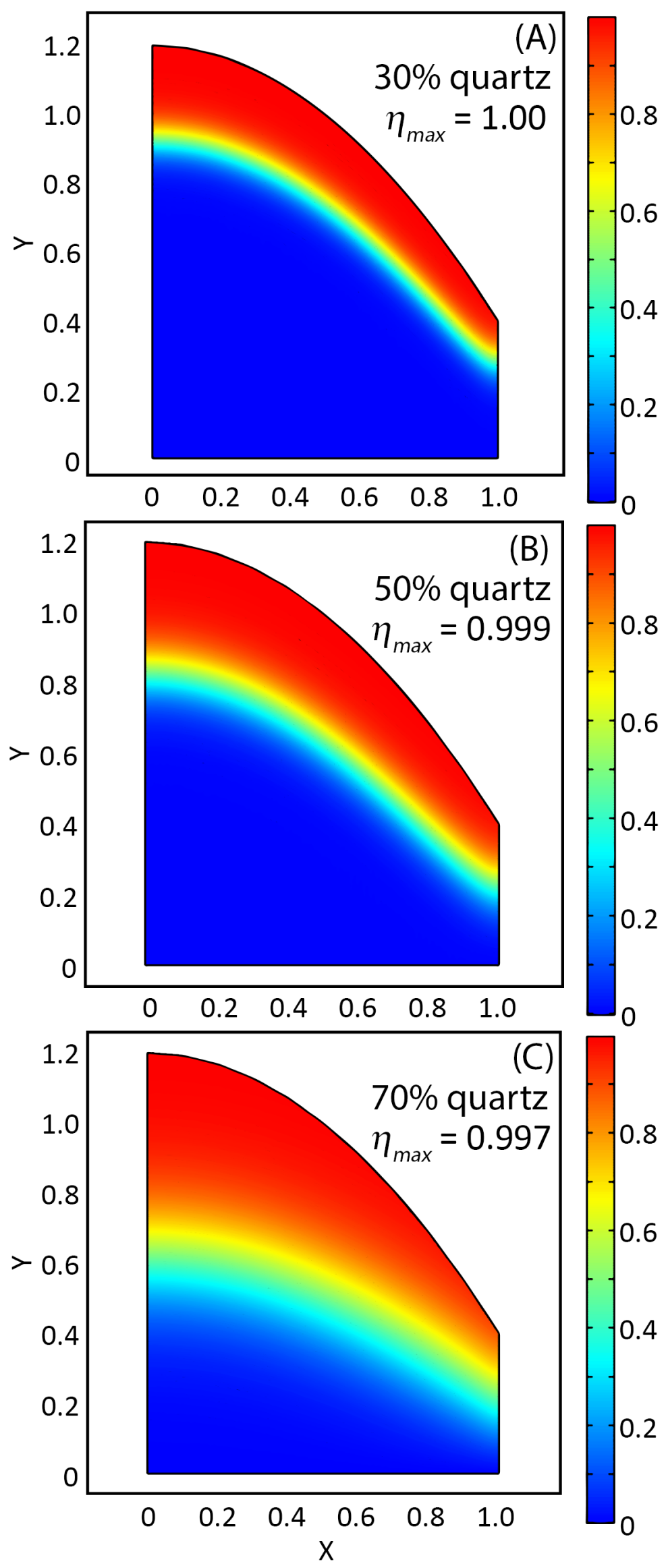




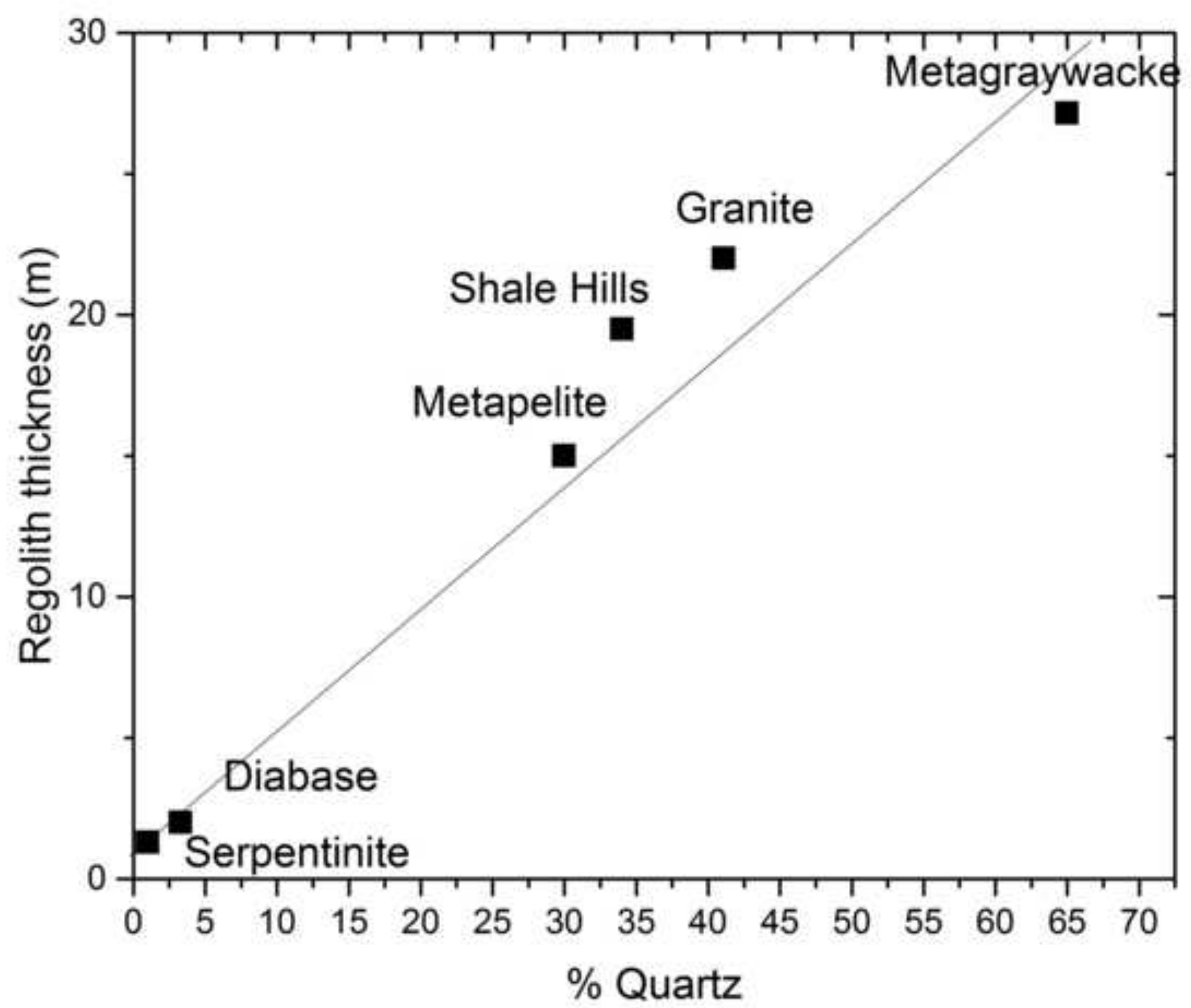




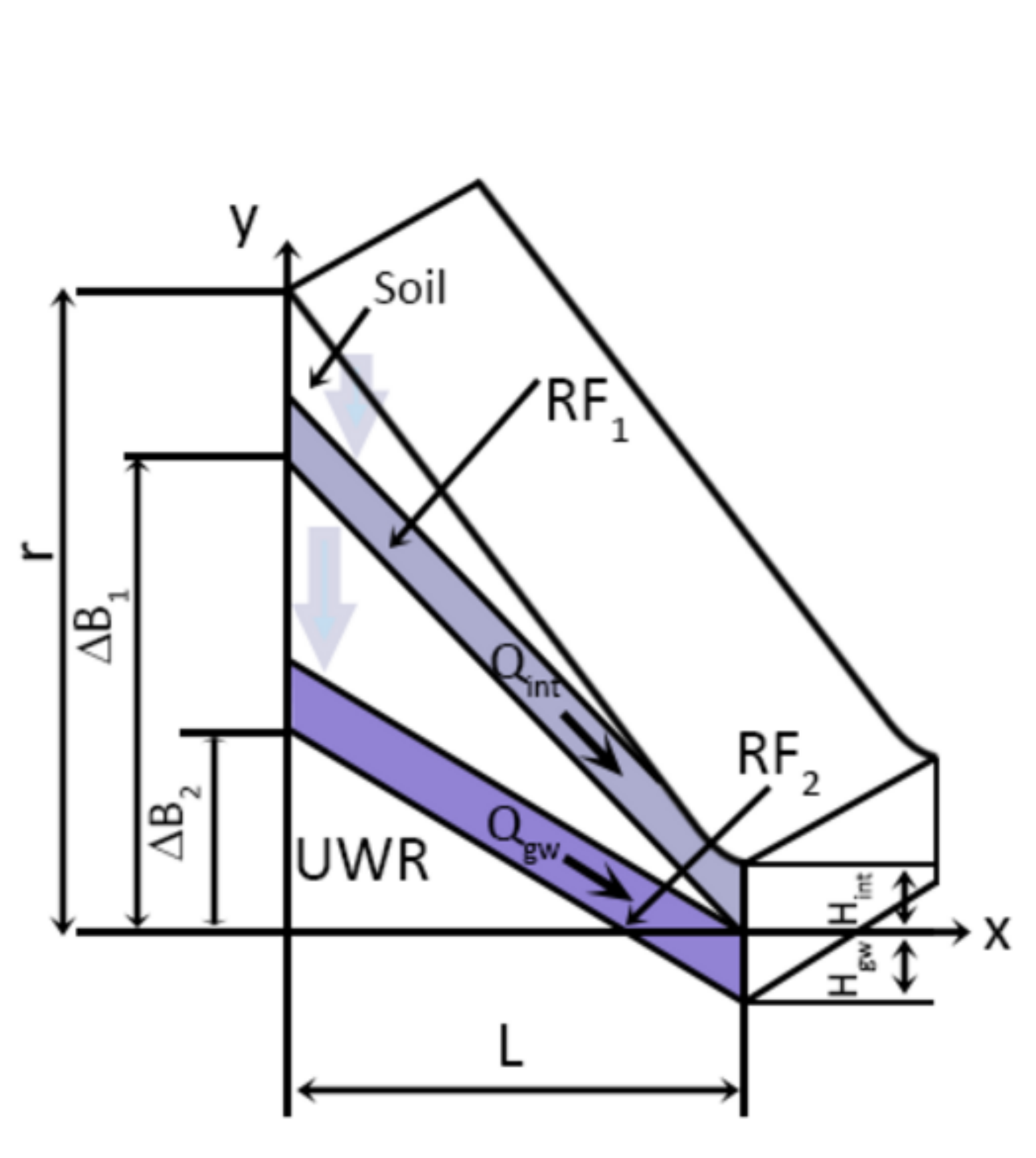

Figure 7 (Color)

)
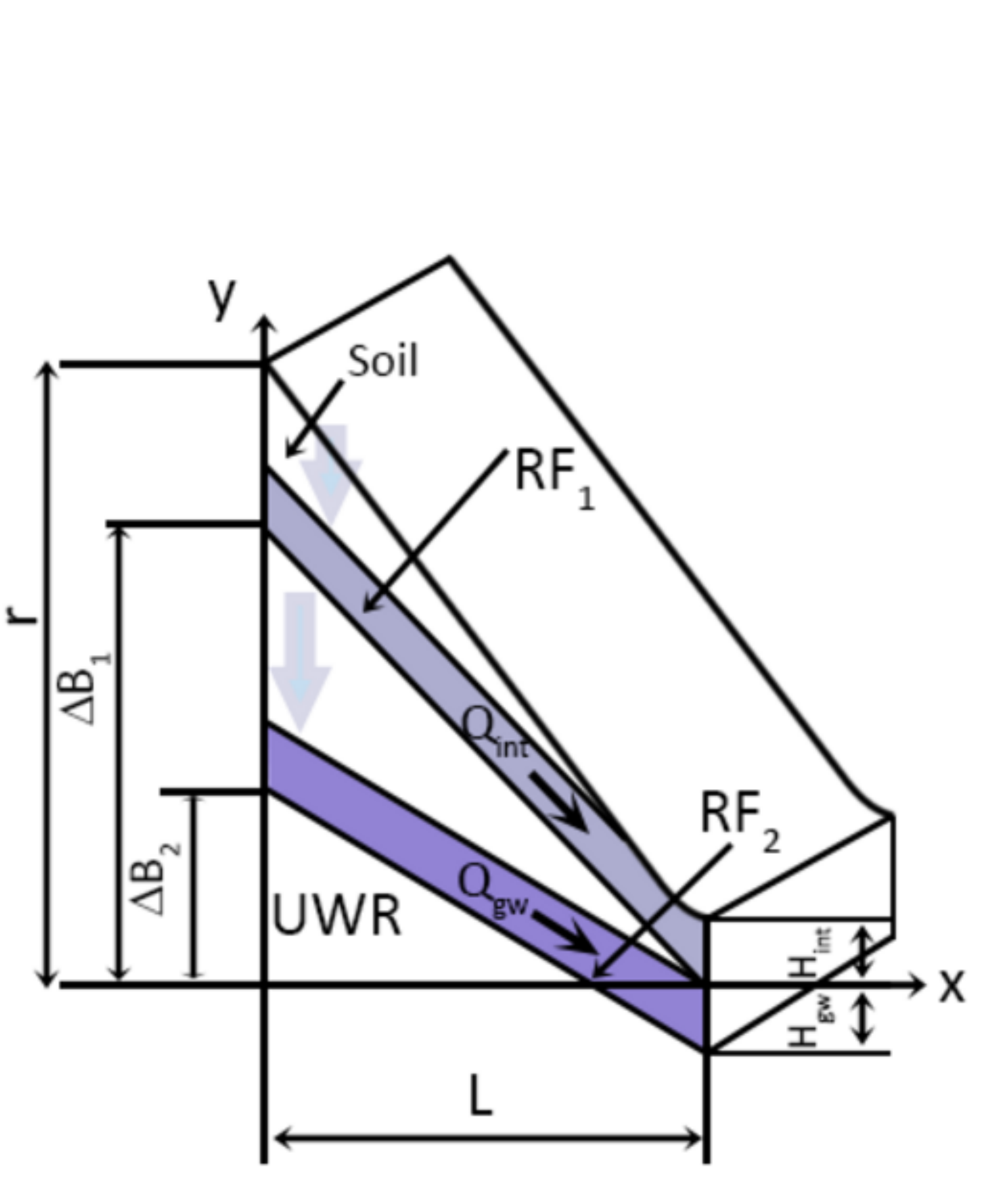
land surface

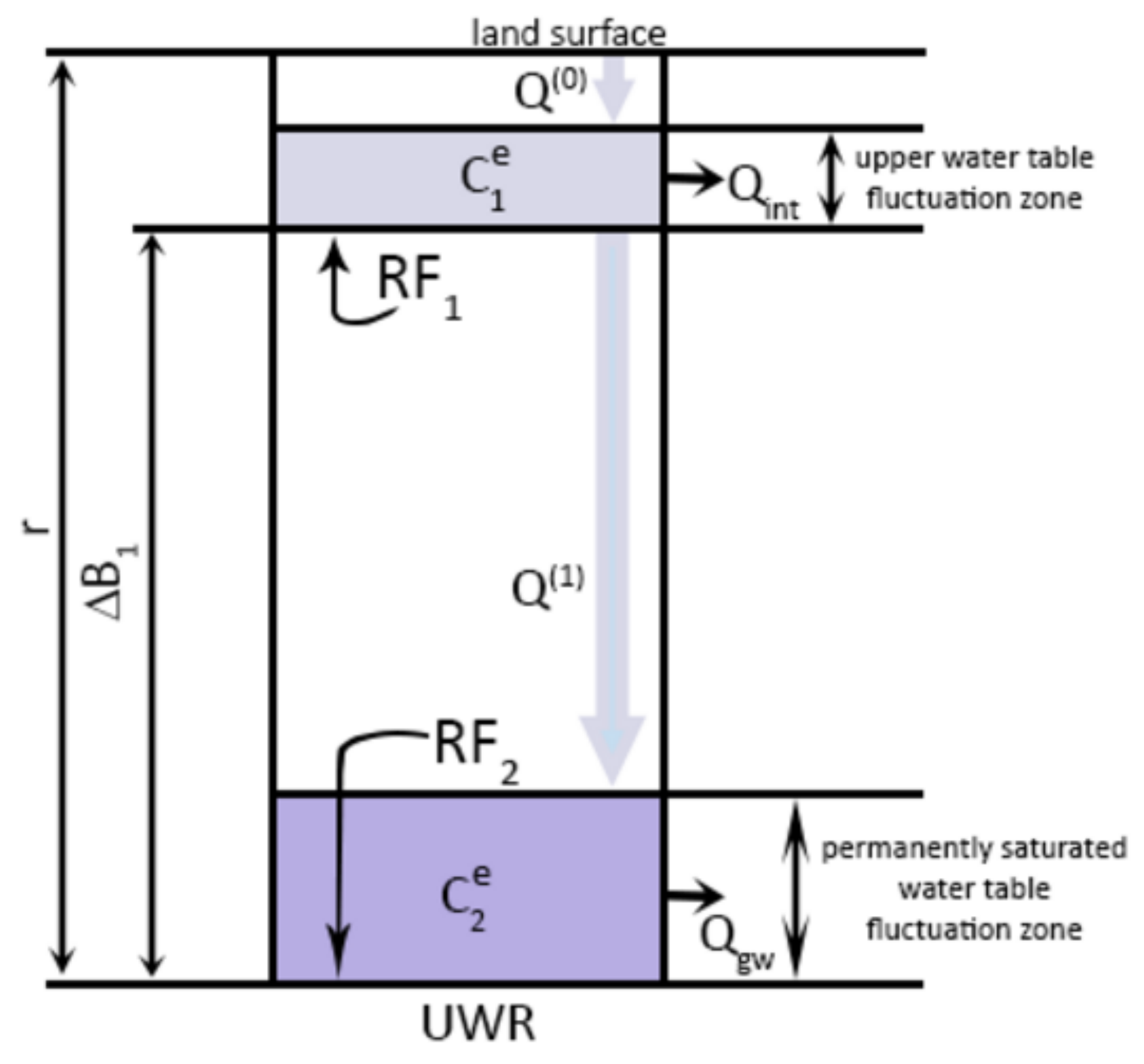

Figure 8 (Color)

(

